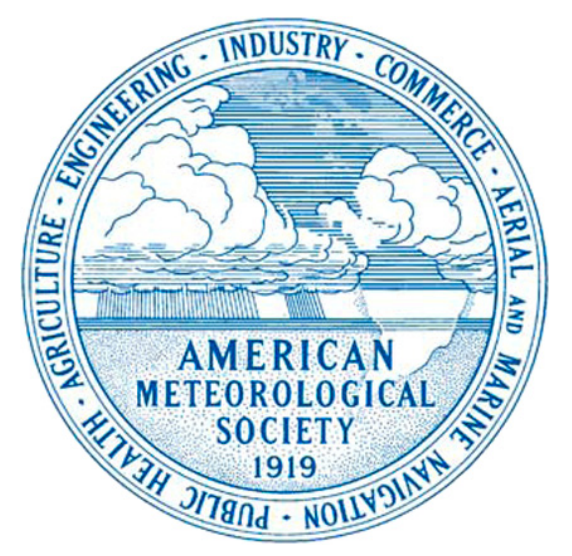

\title{
AMERICAN METEOROLOGICAL SOCIETY
}

\section{Journal of Physical Oceanography}

\section{EARLY ONLINE RELEASE}

This is a preliminary PDF of the author-produced manuscript that has been peer-reviewed and accepted for publication. Since it is being posted so soon after acceptance, it has not yet been copyedited, formatted, or processed by AMS Publications. This preliminary version of the manuscript may be downloaded, distributed, and cited, but please be aware that there will be visual differences and possibly some content differences between this version and the final published version.

The DOI for this manuscript is doi: 10.1175/JPO-D-13-047.1

The final published version of this manuscript will replace the preliminary version at the above $\mathrm{DOI}$ once it is available.

If you would like to cite this EOR in a separate work, please use the following full citation:

Durgadoo, J., B. Loveday, C. Reason, P. Penven, and A. Biastoch, 2013: Agulhas Leakage Predominantly Responds to the Southern Hemisphere Westerlies. J. Phys. Oceanogr. doi:10.1175/JPO-D-13-047.1, in press. 
$1 \quad$ Agulhas leakage predominantly responds to the Southern Hemisphere westerlies

Benjamin R. Loveday

Department of Oceanography, University of Cape Town, South Africa

GEOMAR Helmholtz Centre for Ocean Research Kiel, Germany

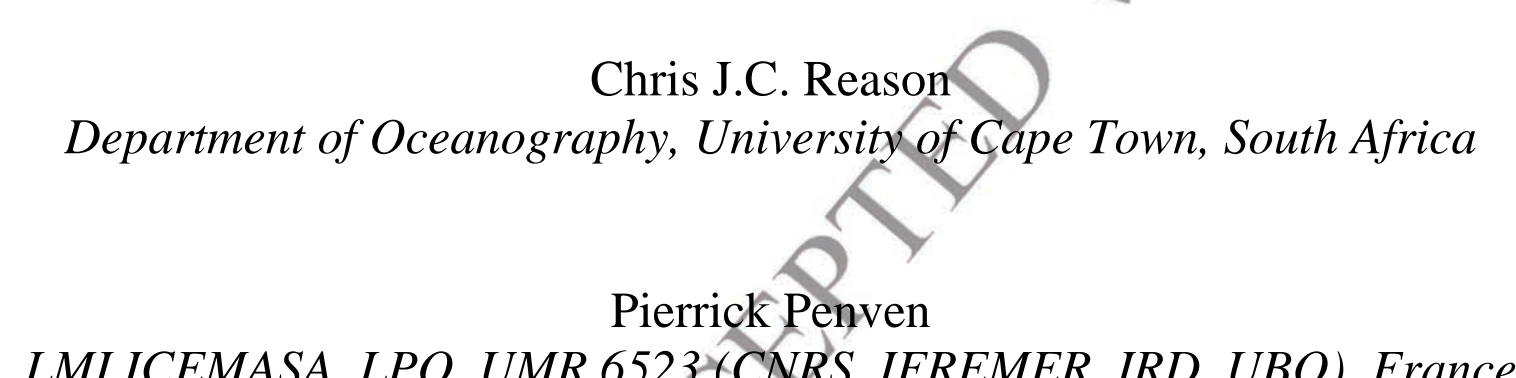

LMI ICEMASA, LPO, UMR 6523 (CNRS, IFREMER, IRD, UBO), France

\section{4}

\footnotetext{
${ }^{1}$ Corresponding author address: Jonathan Durgadoo, GEOMAR Helmholtz Centre for Ocean Research Kiel, 24105, Germany.

E-mail: jdurgadoo@gmail.com
} 
28 The Agulhas Current plays a crucial role in the thermohaline circulation through its

29 leakage into the South Atlantic. Under both past and present climates, the trade winds and

30 westerlies could have the ability to modulate the amount of Indian-Atlantic inflow.

31 Compelling arguments have been put forward suggesting that trade winds alone have

32 little impact on the magnitude of Agulhas leakage. Here, employing three ocean models

33 for robust analysis - a global coarse resolution, a regional eddy-permitting and a nested

34 high-resolution eddy-resolving configuration - and systematically altering the position

35 and intensity of the westerly wind belt in a series of sensitivity experiments, it is shown

36 that the westerlies, in particular their intensity, control the leakage. Leakage responds

37 proportionally to the westerlies intensity up to a certain point. Beyond this, through the

38 adjustment of the large-scale circulation, energetic interactions occur between the

39 Agulhas Return Current and the Antarctic Circumpolar Current that result in a state

40 where leakage no longer increases. This adjustment takes place within 1 to 2 decades.

41 Contrary to previous assertions, our results further show that an equatorward (poleward)

42 shift in westerlies increases (decreases) leakage. This occurs due to the redistribution of

43 momentum input by the winds. It is concluded that the reported present-day leakage

44 increase could therefore reflect an unadjusted oceanic response mainly to the

45 strengthening westerlies over the last few decades. 


\section{1. Introduction}

48 The climatically relevant component of the Agulhas Current system is arguably its inflow

49 into the South Atlantic (de Ruijter et al. 1999). One of the unique features of this western

50 boundary current system is that it redistributes heat and salt not only poleward but also

51 equatorward in the form of Agulhas leakage (Fig. 1). The equatorward injection of warm

52 salty thermocline waters into the Atlantic forms a major part of the return flow towards

53 the North Atlantic, where, through active air-sea interactions at high latitudes, deep

54 waters are formed (Gordon 1986; Gordon et al. 1992; Cunningham and Marsh 2010). In

55 this way, the Agulhas system is considered to be important for global climate (Beal et al.

56 2011) and as a result, the variability of Agulhas leakage on all timescales is of particular

57 interest. In the past, some evidence for leakage reduction during glacial times (Peeters et

58 al. 2004), possibly modulated by a northward migration of the subtropical front south of

59 Africa (Bard and Rickaby 2009), has been inferred from sediment records. At glacial

60 terminations, increase in leakage has been further linked with the recovery of the Atlantic

61 thermohaline circulation (Knorr and Lohmann 2003). Under the current (and future)

62 warming climate, model studies suggest an increasing trend in Agulhas leakage (Biastoch

63 et al. 2009a; Rouault et al. 2009) that result in an overall salinification of the South

64 Atlantic (Biastoch and Böning 2013). The effectiveness of this significant exchange south

65 of Africa for the most part is thought to be linked in one way or another to the wind

66 patterns of the Southern Hemisphere (Biastoch et al. 2009a; Rouault et al. 2009).

67 The Agulhas system is sandwiched between two major wind belts, namely the

68 southeast trades, between the Equator and about $30^{\circ} \mathrm{S}$, and the westerlies, over roughly

$6930^{\circ}-60^{\circ} \mathrm{S}$. With the average latitudinal range of the positive wind stress curl region in 
70 the Indian Ocean extending beyond the termination of the African continent near $34^{\circ} \mathrm{S}$

71 (Marshall and Plumb 2007), the Agulhas Current leaves the continental slope as a free-

72 jet. An interplay between its large inertia and the position of the zero wind stress curl

73 (maximum westerlies) leads to its retroflection (Ou and de Ruijter 1986), a process which

74 also determines the amount of leakage into the Atlantic (de Ruijter et al. 1999; Pichevin

75 et al. 1999; Dijkstra and de Ruijter 2001). Therefore, the variability of Agulhas leakage

76 on all timescales is expected to be connected to the trades and/or westerlies strength

77 and/or position.

78 The trade winds are largely responsible for the inertia of the Agulhas Current.

79 Rouault et al. (2009) and van Sebille et al. (2009) (who used the same model as Biastoch

80 et al. (2009a)) found the contemporary increase in leakage to be linked with the upstream

81 strength of the Agulhas Current. Within their range of model observations, they however

82 disagreed on the sign of the relationship; Rouault et al. (2009) claimed an increase in

83 leakage caused by increase in Agulhas Current, while van Sebille et al. (2009) argued for

84 a decrease in the upstream inertia that leads to an increase in leakage. Both of these

85 studies implied that the trade winds influence leakage magnitude. In a series of realistic

86 global and regional ocean/sea-ice models, Loveday et al. (submitted) showed that the

87 sensitivity of Agulhas leakage to the Agulhas Current transport decreases with increasing

88 horizontal resolution. In the eddy-resolving simulations, large changes in the upstream

89 transport of the Agulhas Current had almost no effect on the magnitude of the leakage.

90 Even though a stronger Agulhas transport did cause the Agulhas Current to break from

91 the shelf further upstream (Ou and de Ruijter 1986), the inertial jet always proceeded

92 south-westward. As a result, despite large localized changes in both mean and eddy 
93 kinetic energy, the annual mean retroflection position remained stable, consistent with

94 observed present-day (Dencausse et al. 2010) and reconstructed past (Franzese et al.

95 2009) measurements, and Agulhas leakage is unaffected. The increase in kinetic energy

96 possibly leads to a recently described turbulent retroflection regime (Le Bars et al. 2012)

97 where leakage is no longer dependent on the incoming transport.

98 Given this apparent decoupling between Agulhas leakage and trade winds, in this

99 study we explore the possible dependency of leakage on the Southern Hemisphere

100 westerlies. We systematically alter the position and magnitude of the westerly wind belt

101 within three model configurations similar to those used by Biastoch et al. (2009a) and

102 van Sebille et al. (2009) (half-degree global, with and without a tenth-degree nest) and

103 Rouault et al. (2009) (quarter-degree regional) in order to achieve robust results. The

104 strategy we employ generally follows the works of Oke and England (2004), Sijp and

105 England (2008, 2009) and Biastoch and Böning (2013). The models are all forced by the

106 same atmospheric data and consistent diagnostics are derived. In so-doing, we aim to dis-

107 entangle the relationship between the magnitude of Agulhas leakage and the westerlies

108 location and strength.

109 Following a description of the models and of our experiment strategy in section 2

110 we explore the equilibrium (section 3) and transient (section 4) leakage response to

111 westerlies change. In section 5 we seek a mechanism explaining the results and then

112 discuss the implications in section 6 before summarizing our main findings in section 7.

\section{2. Model configurations and Experiment Strategy}

114 The three models employed in this study are ORCA05, INALT01 and AGIO. The first

115 two, based on the ocean/sea-ice Nucleus for European Modeling of the Ocean code 
116 (NEMO v3.1.1, Madec (2008)) and developed under the DRAKKAR framework (The

117 DRAKKAR Group 2007) are global models and will be described first. AGIO,

118 summarized thereafter, is a regional model based on the Regional Ocean Modeling

119 System (ROMS, Shchepetkin and McWilliams (2005)) and is described thoroughly in

120 Loveday et al. (submitted). Similar configurations of these models were used by Biastoch

121 et al. (2009a), Rouault et al. (2009) and van Sebille et al. (2009) but with different setups

122 and forcing fields which we hypothesize have led to their conflicting results. To assess

123 this, we performed all experiments under same atmospheric forcing with as much

124 coherence and conformity as possible.

125 a. ORCA05 and INALTO1

126 Both ORCA05 (coarse resolution configuration) and INALT01 (nested configuration)

127 follow an ORCA setup (Madec and Imbard 1996; Barnier et al. 2006). In this setup a tri-

128 polar horizontal grid is used and south of $20^{\circ} \mathrm{N}$, the grid is Mercator-type. Variables are

129 staggered following an Arakawa-C arrangement. In the vertical, the model uses z-

130 coordinates with a total of 46 levels (10 levels in the top $100 \mathrm{~m}$ and a maximum of $250 \mathrm{~m}$

131 resolution at depth). In order to enhance representation of flow near bottom topography,

132 the deepest grid box is allowed to be partially filled (Barnier et al. 2006) in addition to a

133 non-linear bottom friction (Tréguier 1992). A free-slip lateral momentum boundary

134 condition is used. The treatment of tracers is implemented using a Laplacian operator for

135 the lateral diffusion and the Total Variance Dissipation (Zalesak 1979) scheme for

136 advection. Lateral diffusion on momentum uses a bi-Laplacian operator with a vector

137 form advection scheme that conserves energy and enstrophy (Arakawa and Hsu 1990). 
138 Sub-grid scale vertical mixing is calculated explicitly through the turbulent eddy kinetic

139 dependent diffusion scheme (Blanke and Delecluse 1993).

140 ORCA05, with half-degree nominal horizontal resolution, which in the Agulhas

141 region is $\sim 45 \mathrm{~km}$, is an established configuration successfully reproducing the large-scale

142 global circulation (Biastoch et al. 2008a). INALT01 consists of a base global model (that

143 is identical in configuration to ORCA05) and a nest embedded within between $70^{\circ} \mathrm{W}-$

$14470^{\circ} \mathrm{E}$ and $50^{\circ} \mathrm{S}-8^{\circ} \mathrm{N}$ (Fig. 1). The nest refines the horizontal model grid over the

145 Agulhas Current system and South Atlantic 5-folds to a tenth-degree ( 9 km over the

146 Agulhas region). This also implies a 4-fold time-stepping refinement from 36 (base) to 9

147 (nest) minutes. Bathymetry within the nest region is interpolated from ETOPO2 ${ }^{1}$.

148 The horizontal refinement is achieved by adopting the AGRIF (Debreu and Blayo

149 2008) approach whereby both model grids are coupled in a 2-way mode at every base

150 model time-step to provide the nest with open boundary conditions from the base but also

151 enabling the mesoscale dynamics of the nest to permeate into the base. For this reason,

152 neither INALT01's base nor ORCA05 have parameterized mesoscale eddies, a practice

153 that is usually common for models of such resolution class. Eddy parameterization, such

154 as the Gent and McWilliams (1990) scheme, typically mimics the impact of eddies on

155 tracer fluxes as isopycnal diffusion and eddy advection. This has an overall effect of

156 reducing isopycnal steepness. Such parameterization is believed to dampen the influence

157 of the mesoscale dynamics of the nest onto the base. ORCA05 was also run without eddy

158 parameterization in order to allow consistent comparison between both models.

159 INALT01 is an update of AG01 (Biastoch et al. 2009b), the latter has been

160 demonstrated to represent the dynamics of the Agulhas Current and its large-scale impact

\footnotetext{
${ }^{1}$ http://www.ngdc.noaa.gov/mgg/global/relief/ETOPO2/ETOPO2v2-2006/ETOPO2v2g/
} 
161 successfully (Biastoch et al. 2008b,c, 2009a,b; van Sebille et al. 2009). With its wider

162 high-resolution domain encompassing the South Atlantic basin as well as the tropical

163 Atlantic, INALT01 better lends itself to the investigation of the hypothesized impact of

164 Agulhas leakage on the Atlantic heat, freshwater and momentum balances. In addition,

165 the advective pathways between the Agulhas system and the North Atlantic can be

166 further explored. The new configuration simulates successfully two major western

167 boundary currents of the Southern Hemisphere.

168 Prescribing appropriate atmospheric forcing is crucial for ocean modeling. The

169 CORE (v2b, Large and Yeager (2009)) project provides the necessary coherent and

170 globally balanced dataset to drive the model. Through bulk formulation, 6-hourly air-sea

171 fluxes of heat, freshwater and momentum, daily short- and long-wave radiation and

172 monthly rain and snow, are used in conjunction with surface ocean temperatures and

173 velocities, which effectively allow some feedback between ocean and atmosphere. For

174 this study, both climatologically and inter-annually varying CORE fields were used.

175 Ocean-only models often exhibit drifts in properties. In order to constrict such

176 artificial drifts within ORCA05 and INALT01, a $10 \%$ precipitation reduction (which

177 falls within the CORE dataset uncertainty range) north of $55^{\circ} \mathrm{N}$ is implemented in

178 addition to a sea surface salinity restoring over the top $50 \mathrm{~m}$ with a timescale of 8.3 years.

179 This "very weak" salt flux damping is capped at $0.5 \mathrm{~kg} \mathrm{~m}^{-1} \mathrm{~s}^{-1}$ to prevent regions of

180 strong gradients from being excessively damped.

181 Initializing the thermohaline fields with a combined dataset from Levitus World

182 Ocean Atlas $1998^{1}$ and Polar Science Centre Hydrographic Climatology (Steele et al.

183 2001), and starting from rest, ORCA05 is allowed to spin-up for 20 years forced with

\footnotetext{
${ }^{1}$ http://www.esrl.noaa.gov/psd/
} 
184 inter-annually (1978-1997) varying CORE fields. This strategy promotes a stable Atlantic

185 meridional overturning circulation with a reasonable magnitude of $\sim 18 \mathrm{~Sv}$ (Cunningham

186 and Marsh 2010) which, in the previous version (AG01), was 10 Sv (Biastoch et al.

187 2008b). Dynamic equilibrium is reached within the 20 years of spin-up (Fig. 2) and this

188 output is then used to warm-start the experiments outlined in Section 2c.

189 b. AGIO

190 The AGIO configuration (Loveday et al. submitted) is a quarter-degree resolution eddy-

191 permitting implementation of ROMS (Shchepetkin and McWilliams 2005), constructed

192 using ROMSTOOLS (Penven et al. 2008). The domain, which extends from $29^{\circ} \mathrm{W}$ to

$193115^{\circ} \mathrm{E}$ and $48^{\circ} \mathrm{S}$ to $7^{\circ} \mathrm{N}$ on a Mercator grid, spans the Indian and South East Atlantic

194 Ocean basins. AGIO is an extension of the SAfE configuration (Penven et al. 2006)

195 which was used by Rouault et al. (2009). The average grid spacing over the southern

196 Agulhas region is $\sim 23 \mathrm{~km}$. The vertical resolution in AGIO is described by $32 \sigma-$

197 coordinate levels following the GEBCO $1^{1}$ derived bathymetry and stretched towards the

198 surface. The regional bathymetry is selectively smoothed to reduce pressure gradient

199 errors (Haidvogel and Beckmann 1999). Higher order numerics and a third-order,

200 upstream-biased advection scheme reduce dispersion, allowing steep density gradients to

201 be preserved, and enhancing precision for a given resolution (Shchepetkin and

202 McWilliams 1998). The splitting of diffusion and advection via the RSUP3 scheme

203 minimizes spurious diapcynal mixing (Marchesiello et al. 2009). Western boundary

204 currents are selectively damped via a parameterization of horizontal viscosity

205 (Smagorinsky 1963) and sub-grid scale vertical mixing follows a non-local K-Profile

\footnotetext{
${ }^{1}$ http://www.gebco.net/data_and_products/gridded_bathymetry_data/
} 
206 parameterization (Large et al. 1994). The lateral viscosity and diffusion are zero in the

207 domain interior and increase to $1000 \mathrm{~m}^{2} \mathrm{~s}^{-1}$ in the sponge layer within $\sim 200 \mathrm{~km}$ from the

208 domain boundaries. Prognostic variables are connected to the external conditions by an

209 active radiation scheme (Marchesiello et al. 2001). Lateral boundary conditions for all

210 AGIO experiments are derived from the climatological-monthly-mean ORCA05

211 reference experiment, and variability associated with the Antarctic Circumpolar Current

212 is thereby excluded. AGIO is initialized with outputs from the ORCA05 20-year spin-up.

\section{3 c. Experiment Design and Application}

214 The experiments we performed are to some extent similar to those presented by Oke and

215 England (2004) and Sijp and England (2008, 2009). Anomalies applied to the present-day

216 wind patterns (Fig. 3a) were designed to mimic different states in westerlies regime;

217 equatorward and poleward shifts of $\pm 2^{\circ}$ and $\pm 4^{\circ}$ of latitude (Fig. 3b) and intensity

218 changes of $\pm 20 \%$ and $\pm 40 \%$ (Fig. 3c). The values chosen roughly span the range of

219 observed (Swart and Fyfe 2012), $21^{\text {st }}$ century projected (Fyfe and Saenko 2006; Fyfe et

220 al. 2007) as well as past (Hodgson and Sime 2010) changes in westerly winds. These

221 anomalies have a smooth and quasi-sinusoidal shape to avoid any sharp changes or

222 disruptions in the general wind stress curl pattern (that would alter the general pattern of

223 the circulation). Additional design considerations were: (i) Changes to the westerlies

224 were limited to south of $35^{\circ} \mathrm{S}$ such that no changes are applied to the latitudes that would

225 influence the inertia of the western boundary current; (ii) Shifts were constructed based

226 on the latitudinal location of the maximum wind stress and the total energy input kept

227 constant; (iii) The meridional wind stress component were unchanged. These

228 considerations imposed limits to the extent the westerlies could be altered. 
The resulting anomalies were reproduced onto the respective model-grids. Out of

230 the 8 anomalies (Fig. 3b, c), a total of 15 anomaly fields were produced (Table 1). For

231 some anomalies, in particular the SHW+40\% anomaly (westerlies intensity increase by

$23240 \%$ ), in addition to changing the intensity of the wind stress, we also altered the region

233 over which these anomalies were applied (Fig. 4). These geographical decompositions

234 attempt to determine the influence the Antarctic Circumpolar Current may have on the

235 Agulhas system. For these cases, additional smoothing was applied along the boundaries.

236 The 2-dimensional wind anomaly fields were added after calculation of the wind stress.

237 Thus, the application influences the momentum and not the buoyancy input to the

238 ocean/sea-ice. This strategy follows Biastoch and Böning (2013) who performed a similar

239 experiment within AG01.

240 All three models, sharing the same 20-year spin-up history, were forced under

241 background CORE climatological forcing (Large and Yeager 2009). Fig. 2 exemplifies

242 the adjustment of the models. A relatively fast adjustment in volume integrated kinetic

243 energy to changes in resolution and forcing (application of anomaly) is noted. The

244 reference experiments were integrated for 30 years before application of the anomalies.

245 At first they were applied with a linear ramp-up over one year (model year 31) and

246 subsequently in full. Reference and sensitivity simulations ran parallel from model year

247 31. After two decades of parallel integration, analysis for all simulations was performed

248 for a common period of 10 years (model years $51-60$ ). The increasing kinetic energy

249 after model year 45 in the global models for the SHW+40\% examples shown in Fig. 2

250 reflects the transient response of the Agulhas system to the enhanced winds. This is

251 discussed in Section 4. Some selected experiments were extended, as outlined in Table 1. 
252 The models were additionally integrated under inter-annually varying surface forcing,

253 providing 6 decades (1948 - 2007) of hind-cast simulations.

\section{4 d. Model Validations}

255 Given the dominance of mesoscale variability, direct one-to-one comparison with

256 features observed during oceanographic expeditions cannot be expected, even though a

257 high-frequency, inter-annually varying forcing is used. However, time-mean properties

258 and statistical representation of the variability ought to be comparable. ORCA05 is an

259 established configuration of NEMO (Biastoch et al. 2008a). Both AGIO and INALT01

260 are updates of previously thoroughly tested configurations; SAfE (Penven et al. 2006)

261 and AG01 (Biastoch et al. 2008b,c,2009b; van Sebille et al. 2009,2010) respectively.

262 Within ORCA05, the Agulhas Current is represented by a continuous flow that begins in

263 the Northern Mozambique Channel with the only source of variability originating south

264 of Madagascar. The current retroflects and occasionally produces some large unrealistic

265 rings. In contrast, within AGIO and INALT01, where the first baroclinic Rossby radius of

266 deformation is resolved (20 - 50 km in this region, Chelton et al. (1998)), a broad

267 spectrum of mesoscale activity is observed in the known source regions of the Agulhas

268 Current as well as a more realistic representation of the diverse range of features typically

269 found in the Cape Cauldron, namely Agulhas Rings, Cyclones and filaments among

270 others (Boebel et al. 2003). Fig. 5 portrays the models reproduction of the mean

271 circulation as well as the mesoscale variability of the Agulhas system compared to that

272 observed from satellite altimetry (Fig. 5a). The mean circulation is successfully

273 represented by all three models; the details of the variability do however differ. 
275 Measuring Agulhas leakage is no simple task. Being highly intermittent, leakage occurs

276 predominantly through Agulhas rings. However, other features such as cyclones and

277 filaments also contribute to the Indian-Atlantic transport. Therefore, direct quantification

278 of Agulhas rings crossing the Cape Basin would likely underestimate leakage magnitude

279 (de Ruijter et al. 1999), while full-depth Eulerian measurements would over estimate it.

280 Attempts at estimating leakage using optimized Eulerian methods have been made (van

281 Sebille et al. 2010) but the skills of such methods have not been tested across models

282 with different horizontal and vertical resolutions. From float and drifter observations,

283 Richardson (2007) estimated leakage to be at about 15 Sv.

284 Here, we estimated annual values of leakage using a Lagrangian method

285 following the works of Speich et al (2001), Biastoch et al. (2008b, 2009a) and van Sebille

286 et al. (2009). Water parcels were released every 5 days for one year over the full-depth of

287 the poleward-flowing Agulhas Current across a zonal $300 \mathrm{~km}$ long segment at $32^{\circ} \mathrm{S}$. Each

288 parcel had a defined transport of max. $0.1 \mathrm{~Sv}$ and the total number of parcels released

289 were representative of the 5-daily magnitude of the Agulhas Current. The parcels were

290 then advected using the model's velocity fields for a total period of five years and

291 aggregated across predefined sections. The integration period optimally allowed $98 \%$ of

292 the parcels to exit the domain shown in Fig. 5d. Agulhas leakage is defined as that

293 portion of the Agulhas Current exiting the domain through the Good-Hope section

294 (Ansorge et al. 2005) in the Cape Basin (Fig. 5b). The advantage of this method is that it

295 can be applied to all three models without the need for additional model-specific

296 redefinitions, allowing direct inter-model comparisons. The southward transport of the 
297 Agulhas Current at $32^{\circ} \mathrm{S}$ for model years $51-60$ of the three REF experiments are $71.9 \pm$ $298 \quad 0.7,72.9 \pm 3.1$ and $64.6 \pm 2.6 \mathrm{~Sv}$ for ORCA05, AGIO and INALT01 respectively. The

299 corresponding reference leakage values for the same period are 31.9 $\pm 1.5,31.5 \pm 1.4$ and

$300 \quad 16.6 \pm 1.7 \mathrm{~Sv}$ respectively. It is clear that leakage is markedly influenced by the regional

301 mesoscale (Biastoch et al. 2008c).

3023 . Agulhas leakage equilibrium response

303 Owing to the different reference values of Agulhas leakage in the three models, we adopt

304 the percentage change with respect to reference as a measure of leakage response. This

305 places all reference values at the origin. The 10-year-mean (model years $51-60$ ) leakage

306 response to changes in position (Fig. 6a) and intensity (Fig. 6b) of the westerlies display

307 three clear patterns. Firstly, within the global models, an equatorward (poleward) shift in

308 westerlies produces an increase (decrease) in leakage. Note that AGIO's southern

309 boundary at $48^{\circ} \mathrm{S}$ makes shift experiments not sensible. Secondly, increasing westerlies

310 intensity generally produces more leakage but the relationship is not completely linear.

311 Finally, leakage responds preferentially, and the magnitude of that response is more

312 pronounced when changes are applied to the westerlies intensity than shifts. For this

313 reason, we will concentrate on the intensity cases and return to the shifts towards the end.

314 Interestingly, for strong wind stress in Fig. 6b, both global models simulate very little

315 leakage change and even reduction compared to the reference values. Conversely, a $20 \%$

316 and $40 \%$ reduction in wind stress produces approximately the same amount of leakage

317 decrease. Consistent with Le Bars et al. (2012), there appears to be a threshold in leakage

318 response to increased westerlies. 
In order to investigate the reason for this threshold, we focus on two extreme

320 intensity cases, $\mathrm{SHW} \pm 40 \%$ within ORCA05. The Agulhas system, forming part of the

321 subtropical gyres of the south Atlantic and south Indian Oceans (Ridgway and Dunn

322 2007) and bounded by the Antarctic Circumpolar Current, potentially could be influenced

323 by numerous external factors. In an attempt to therefore distinguish between local and

324 large-scale wind impact on leakage, a geographical decomposition of the SHW $\pm 40 \%$

325 experiments was performed (Fig. 4a-c). We favored the use of the coarse resolution

326 ORCA05 model since it is computationally less demanding. The response shown in Fig.

$3276 \mathrm{c}$ reveals that the overall leakage response consists of the direct influence of the

328 westerlies acting locally (over the Agulhas Retroflection and Cape Basin region) on the

329 magnitude of the leakage and on the indirect influence of the winds via the adjacent

330 currents. INALT01, the configuration that mimics the known complexity of the Agulhas

331 system with the highest degree of semblance, reproduces the general behavior in leakage.

332 Leakage response within INALT01-SHW+40\% with LOCAL decomposition shows that,

333 despite the overestimation of absolute leakage values within the coarse resolution model,

334 the change in leakage is consistent. The decompositions further indicate that the threshold

335 in leakage change originates from the large-scale circulation, within which the Agulhas

336 system is embedded.

337 This hypothesis is tested by employing the regional model, AGIO, whose domain

338 excludes much of the large-scale circulation (Loveday et al. submitted). The global ocean

339 influences this regional model through lateral boundary conditions derived from

340 climatology of the ORCA05-REF simulation. Here, leakage response is quasi-linear,

341 monotonously increasing with strengthening westerlies (Fig. 6b). This suggests that, with 
342 a constant climatological representation of large-scale circulation, in particular that of the

343 Southern Ocean, the portion of the westerlies felt within AGIO's southern domain $\left(35^{\circ} \mathrm{S}\right.$

$344-48^{\circ} \mathrm{S}$ ) does not cause a threshold in leakage response. Altering the boundary conditions

345 to that derived from the ORCA05-SHW+40\% experiment (red cross in Fig. 6b),

346 effectively allows for an assessment of the influence a different Southern Ocean state

347 have on leakage. In this case, leakage behavior is similar to that of the two global models,

348 supporting the hypothesis that the threshold observed in leakage (Fig. 6b) originates from

349 the large-scale circulation.

350 4. Agulhas leakage transient response to increased $351 \quad$ westerlies

352 For the purpose of exploring the time dependency of Agulhas leakage response to

353 increased westerlies, we focus on the SHW+40\% case and expand the ORCA05

354 simulations to beyond the 10 years of common analysis. Fig. 7 shows the time evolution

355 of leakage and other parameters associated with the greater Agulhas system. Presented,

356 are the annual values beginning from model year 31, which is when the anomaly fields

357 are applied. Linear trends calculated from the reference experiment were removed from

358 all runs. Under background climatological forcing, these minor trends (between $0.1 \%$

359 and $2.5 \%$ of the reference values per decade) represent the inherent numerical drift that

360 can reasonably be assumed to be similar in all simulations. The BASIN and LOCAL

361 decompositions are overlaid. Following a fast initial adjustment, three distinct stages in

362 leakage behavior in the ORCA05-SHW+40\%-FULL case (red curve on Fig. 7) can be

363 noted; (i) A proportional increase (model year 34 -47) followed by (ii) a rapid decline 
364 (model year 47 - 50) and finally (iii) return to and decadal modulation around reference

365 values (beyond model year 50).

366 Stage-1: Lasting for about a decade, during Stage-1, the westerlies acting both

367 locally and outside the Agulhas region contribute towards increasing the leakage. This

368 produces an overall proportional response (40\% increase in winds resulting in $40 \%$

369 increase in leakage), with a 1:3 ratio between LOCAL and BASIN. During Stage-1, the

370 mean value of leakage for the FULL experiment is significantly different at the $99 \%$

371 confidence level (Welch's t-test) from the mean leakage value of the reference

372 experiment. As anticipated, no change is observed in the Agulhas Current, the Agulhas

373 Return Current (ARC) and Mozambique throughflow, since surface forcing is unchanged

374 equatorward of $35^{\circ} \mathrm{S}$. The Antarctic Circumpolar Current (ACC) and south-west Indian

375 sub-gyre, during that period, adjust to the altered forcing, which thereafter determines the

376 timescale of the leakage response. Note that, we opt to measure the barotropic ACC

377 transport south of the African continent, the region that is most likely to impact the

378 Agulhas system. Qualitatively, there is little difference from measuring at other choke

379 points, at Drake Passage for example, where the reference value of ACC transport is

380 about $130 \mathrm{~Sv}$, falling within observed ranges (Meredith et al. 2011).

381 Stage-2: Happening rapidly, within 4 model years $(47-50)$, the decline appears

382 to occur indirectly as a result of the large-scale circulation adjustment. Without the large-

383 scale adjustment, a local increase in westerlies would maintain an increased leakage. The

384 decline coincides with the peak in ACC, the increase in ARC transport and variability,

385 and owing to the subtropical gyre spin-up, the increase in Mozambique throughflow. The

386 Agulhas Current also begins to respond accordingly. 
388 falls within the variability range of the reference experiment (with some decadal

389 variations around it). For Stage-3, the mean leakage value of the FULL experiment is

390 significantly not different at $99 \%$ confidence level from the reference value. In response

391 to a $40 \%$ increase in westerlies, the ACC stabilizes to $20 \%$ above reference (Fig. 7).

392 The strengthened sub-gyre results in the increase in Mozambique Channel flow (by 25

$393 \%$ ) and subsequent downstream increase of the Agulhas Current (by 5\%). This Agulhas

394 Current transport increase occurs as an indirect effect of the westerlies increase. No

395 change in the East Madagascar Current transport is noted (not shown). The ARC speed

396 remains at an increased level ( $23 \%$ above reference values), with a $\sim 60 \%$ increase in

397 variance. Towards the end of the simulation (model year 90 onwards), due the increased

398 wind stress curl acting only over the southern portion of the subtropical gyres, the

399 stronger sub-gyre meridionally contracts and zonally widens. This is subsequently seen in

400 a slight reduction in Mozambique throughflow and Agulhas Current transport. The return

401 of leakage to reference values occurs due to the large-scale circulation, as suggested by

402 the BASIN experiment.

403 Fig. 8 shows the equivalent within INALT01. Comparing the two global models

404 provides a way of diagnosing the impact mesoscale activities of the wider Agulhas region

405 have on the leakage response. Perhaps surprisingly so, but as already seen in Fig. 6, the

406 general response to westerly winds increase is not altered. The adjustment happens

407 quicker, and Stage-3 is reached $2-3$ years earlier. To test the impact of resolution on

408 domain decomposition, the LOCAL experiment (only decomposition falling entirely

409 within INALT01's nest boundaries) was repeated within INALT01. The response is as 
410 anticipated similar (Figs. 6b and 8). The fact that the models agree in the response,

411 irrespective of resolution, points towards an underlying mechanism that is to some extent

412 resolution independent.

413 The response seems to be linked to the development of the ACC. In the Atlantic

414 sector of the Southern Ocean, an increase in westerlies promotes a spin-up of the Weddell

415 gyre and, due to an increased pressure gradient, also its expansion (not shown). This in

416 turn, leads to an overall increase in the width of the circumpolar current in the Atlantic.

417 Within the two global models, the dynamic front between the supergyre and the ACC

418 regime can be diagnosed from the zero barotropic stream-function line (see Fig. 3a).

419 During Stage-3, immediately south of the leakage corridor, this boundary migrates by $\sim 2^{\circ}$

420 equatorward.

421 In the Southern Ocean, resolving eddies is known to be important (Hallberg and

422 Gnanadesikan 2006; Böning et al. 2008; Spence et al. 2010). The ACC within INALT01

423 is represented at the same resolution as within ORCA05. Owing to the 2-way nesting

424 scheme adopted for INALT01 and the requirement for consistent comparisons across

425 models, the choice has been made not to parameterize eddies in ORCA05. However in

426 order to assess the dependence of the 3-stage response on firstly Southern Ocean eddies

427 and secondly on initial conditions, we repeated the ORCA05-REF and ORCA05-

428 SHW+40\%-FULL experiments including the initial 20-year spin-up with parameterized

429 eddies (Gent and McWilliams 1990). Thickness diffusivities used are capped at $1000 \mathrm{~m}^{2}$

$430 \mathrm{~s}^{-1}$ but vary spatially and temporally, increasing with stratification and isopycnal slope.

431 These simulations showed the same 3-stage behavior in leakage response (including the 
432 magnitude of the Stage-1 increase), with the only difference being a prolonged Stage-2

433 (figure not shown).

434 Seeking to confirm that the ACC generally influences Agulhas leakage, three

435 additional experiments were undertaken. In these experiments, the SHW+40\% anomaly

436 field was further decomposed geographically and applied within ORCA05 (Fig. 4d-f).

437 Fig. 9 shows the general behavior in ACC-B and ACC-L following the same 3-stage

438 pattern as for FULL (Fig. 7). Within the given time frame, no response is seen when the

439 ACC-P decomposition is applied, potentially indicating that the westerlies acting over the

440 Pacific Ocean, Drake Passage and south of Australia, under this set-up, have no direct

441 immediate impact on leakage. A possible reason for this would be that the westerlies,

442 generally weaker in strength and lying about $5^{\circ}$ poleward in the Pacific compared to the

443 Indian-Atlantic sector (Fig. 3), are not aligned to the core of the applied anomaly. The

444 response in ACC-B, similar in magnitude to that of FULL, suggests that the winds in the

445 region $18^{\circ} \mathrm{W}-115^{\circ} \mathrm{E}$, corresponding to the region of maximum climatological westerlies

446 (Fig. 3), sets the leakage response. Further confirming the ACC's influence, ACC-L, a

447 poleward extension of the LOCAL application, shows an initial increase of the same

448 magnitude as LOCAL and a subsequent 3-stage leakage response.

449 The time scale is set by the ACC. Following the ACC peak, both the leakage and

450 ARC (transport and variance) react with a decline and increase respectively (Figs. 7 - 9).

451 Averaging over two 5-year periods reveals that in Stage-1, the leakage increase is

452 coincidental with an increased eddy kinetic energy in the Cape Basin but a decrease in

453 the retroflection region (Fig. 10a,c). Flowing adjoined and unidirectional to each other,

454 the interaction between the ACC and the ARC become important in Stage-3, where both 
455 the retroflection and the ARC become more energetic and variable (Figs. $7-9,10 \mathrm{~b}, \mathrm{~d}$ ).

456 This is characteristic of a turbulent retroflection regime (Le Bars et al. 2012). This

457 regime, which occurs at strong winds, leads to the increased volume transport (seen in

458 Stage-1 as increased leakage) to be lost through an enhanced interaction between the

459 ARC and the ACC.

460 5. Mechanism of leakage response to the westerlies

461 The region of positive wind stress curl in the South Indian and South Atlantic oceans

462 roughly lies between $15^{\circ} \mathrm{S}$ (maximum trades) and $50^{\circ} \mathrm{S}$ (maximum westerlies). The wind

463 stress curl yields negative Ekman vertical velocities (i.e. pumping) over this region,

464 which promotes an equatorward Sverdrup transport of the interior (Marshall and Plumb

465 2007). Fig. 11 schematically portrays the proposed mechanism of leakage response to

466 changes in the westerlies. Increasing the westerlies in the manner presented in this study

467 leads to an increased wind stress curl between the latitudes $35^{\circ}$ and $50^{\circ} \mathrm{S}$. The

468 equatorward interior flow across the southern portion of the supergyre is therefore

469 enhanced. In Fig. 11, this is depicted along $40^{\circ} \mathrm{S}$, which roughly is the latitude of

470 separation between the westward flowing Agulhas leakage and the eastward flowing

471 Agulhas Return Current. By construction no change is applied to the winds at the

472 latitudes of the Agulhas Current, north of $35^{\circ} \mathrm{S}$. Through continuity, the increased

473 meridional transport must result in a westward mass transport towards the South

474 America. Closing the circulation, the western boundary current subsequently increases.

475 Figs. $6 \mathrm{~b}$ and $6 \mathrm{c}$ (gray lines) also show the change in theoretical meridional interior

476 flow (Sverdrup transport) along $40^{\circ} \mathrm{S}$ resulting from the added intensity anomalies. As

477 anticipated, the change in Sverdrup transport is a linear function of the change in wind 
478 stress curl. Our results show that leakage change within the global models follows the

479 proportional Sverdrup transport change over the entire time-series for the reduced

480 westerlies cases (Fig 6b) and during Stage-1 of the intensified westerlies simulations

$481 \quad$ (Figs 7 and 8).

482 In the portrayal shown in Fig. 11, leakage corresponds to the westward flow south

483 of the African continent and is a passive component of the supergyre circulation. This has

484 three major implications. Firstly, it suggests that the process determining leakage would

485 be independent of retroflection energetics. In partial support for this, we showed that

486 eddy kinetic energy of the retroflection in Fig. 10 matches in sign with neither the initial

487 increase in leakage of Stage-1 nor the return to reference values in Stage-3. Eddy kinetic

488 energy of the retroflection is increased in Stage-3 compared to reference levels, while

489 leakage is unchanged. Therefore, there seems to be no link between the energetics of the

490 retroflection and the process behind leakage. Secondly, it backs up the conclusion of

491 Loveday et al. (submitted) who showed leakage to be decoupled from changes in the

492 Agulhas Current. During Stage-1, large response in leakage occurs without any change in

493 Agulhas Current. In Stage-3, the increase in Agulhas Current (an indirect consequence of

494 the westerlies increase) results in no change in leakage. Thirdly, as noted in Figs. $6-8$,

495 the general pattern of leakage response to the westerlies change is reflected at all

496 resolutions; in other words, irrespective of the form of leakage. It is important to mention

497 here that we do not claim that leakage follows Sverdrup dynamics since non-linearity

498 plays a crucial role in determining the amount of water entering the South Atlantic. What

499 we noticed is that, given a change in the westerlies, leakage responds in the same way the

500 interior adjustment (described by the Sverdrup balanced) does. 
Agulhas leakage response is transient (Figs $7-9$ ). The time dependency is a

502 question of wave propagation, in particular internal planetary waves, similar to the

503 process that communicates the dynamical imprint of leakage across the South Atlantic

504 (van Sebille and van Leeuwen 2007, Biastoch et al. 2008b). Rossby waves set the

505 adjustment time of the ocean to large-scale forcing. The initial rapid oceanic adjustment

506 to the applied high-frequency wind forcing prior to Stage-1 (model years $31-33$ ) is a

507 result of the fast propagation of barotropic Rossby waves, which establishes the Sverdrup

508 balance. Meanwhile, the westerly winds influence induces a baroclinic adjustment of the

509 eastward flowing ACC on decadal timescale. Additional controls, such as its width, its

510 variability and buoyant convection within and outside of the current further influence the

511 adjustment timescale of the ACC (Allison et al. 2011). The timing in Figs. 7 - 9 suggests

512 that the interaction between the ACC and the Agulhas system become important after 1 -

5132 decades. The decrease in leakage in Stage-3 is preceded by an increasing variability of

514 the ARC, which occurs when the ACC reaches its peak. The precise mechanism behind

515 this interaction is beyond the scope of this study. Since both currents are unidirectional

516 and adjacent, meridional exchanges in lateral momentum and tracers between them may

517 be a likely explanation.

518 Thus far, we focused on the impact of westerlies intensity on the Agulhas system.

519 As noted earlier, idealized equatorward shifts of the westerly wind belt induces an

520 increase in leakage (Fig. 6a). This occurs as a result of the redistribution of momentum.

521 Our application of a northward shift of the westerlies strengthens the wind stress curl

522 between $35^{\circ}$ and $45^{\circ} \mathrm{S}$, while reducing it over the core of $\mathrm{ACC}\left(45^{\circ}-60^{\circ} \mathrm{S}\right)$. The overall

523 effect is similar to an increase in westerlies over the southern portion of the Indian Ocean 
524 subtropical gyre which leads to an increase in leakage. In this case, leakage remains at a

525 constant increased level (persistent Stage-1) and a weaker ACC does not result in leakage

526 to be hampered. The opposite for poleward shifts also holds; reduced northward Sverdrup

527 transport across the southern boundary of the supergyre boundary leads to reduced

528 leakage. Towards the end of the SHW-4 simulation, there is an indication that the leakage

529 further decreases, exacerbated by an increased ACC which stimulates an enhanced

530 interaction with the retroflection and ARC. This, once again, is dynamically consistent as

531 described above.

532 6. Discussion

533 There is the common belief that a displacement of the zero wind stress curl line

534 equatorward (poleward) would narrow (widen) the gateway south of Africa allowing less

535 (more) leakage (Zahn, 2010). Our result shows the converse. Paleoceanographic

536 interpretations propose that, on centennial-millennial timescales, a displacement of the

537 subtropical front at the northern boundary of the ACC south of Africa, concomitant with

538 shifts and intensity changes in the westerlies, could be a major driver in modulating the

539 amount of leakage (Peeters et al. 2004; Bard and Rickaby 2009; Caley et al. 2012). In our

540 series of experiments, we observed no significant change in the latitudinal position of the

541 hydrographically-defined subtropical front (maximum temperature gradient) south of

542 Africa in response to changes in position of the zero wind stress curl line. However, we

543 cannot emphatically conclude that the front does not respond to westerly changes, since

544 we did not apply a corresponding thermohaline forcing. Our ocean/sea-ice only

545 simulations addressed the transient response of the Agulhas system. Processes such as

546 deep and bottom water formation, which indirectly respond to changing wind patterns, 
547 would in the long term affect the hydrography of the Southern Ocean leading to possible

548 shifts of its fronts (Spence et al. 2010; Downes et al. 2011; Graham et al. 2012).

549 During the Last Glacial Maximum ( 20 kyears ago), leakage reduction (Peeters et

550 al. 2004; Franzese et al. 2006), and possible ACC increase (Franzese et al. 2006; Otto-

551 Bliesner et al. 2006) with no change in retroflection position (Franzese et al. 2009) have

552 been suggested. There is, however, large uncertainty regarding the state of the Southern

553 Hemisphere winds during glacial times (Kohfeld et al. 2013). To name but a few

554 examples of recent studies, Anderson et al. (2002) and Wyrwoll et al. (2000) reported an

555 intensifying poleward displacement of the westerly jet; Rojas et al. (2008) concluded a

556 decrease with no significant latitudinal shift while Toggweiler et al. (2006) deduced an

557 equatorward shift. It is therefore not possible, given the present limited knowledge of the

558 wind patterns of the Last Glacial Maximum, to confirm whether or not the dependency of

559 Agulhas leakage on the westerlies was dominant. Nonetheless, a leakage reduction

560 accompanied by a more vigorous ACC would be in line with our results.

561 Of current relevance, models simulate an increase in contemporary Agulhas

562 leakage (Biastoch et al. 2009b; Rouault et al. 2009). Biastoch et al (2009b) proposed that

563 a poleward shift in contemporary westerlies is responsible for this increase. Swart et al.

564 (2012) questioned the robustness of such a latitudinal shift in present-day westerlies in an

565 analysis of various coupled climate model products as well as observational reanalyzes

566 and found that instead significant strengthening of the westerlies rather than shift has

567 occurred. In the last 40 years, the westerlies have increased by about $25 \%$ (Fig. 12). We

568 showed that leakage initially responds proportionally to increased westerlies (Stage-1 in

569 Figs. 7 and 8). In Fig. 12, this is reflected by the linear relationship for the SHW+20\% 
570 and SHW $+40 \%$ cases. Note that Fig. 12 shows the area-averaged $\left(20^{\circ} \mathrm{W}-140^{\circ} \mathrm{E}, 35^{\circ}-\right.$

$57165^{\circ} \mathrm{S}$ ) change in westerlies and not the change in maximum zonal-averaged westerlies.

572 Also shown are decadal averages in leakage change derived from the hind-cast

573 experiments of ORCA05 and INALT01. Given the strong linear relationship $(\mathrm{r}=0.98$

574 and 0.96 for ORCA05 and INALT01 respectively), similar to that of the sensitivity

575 experiments, we can conclude that the upward trend in leakage reported by Biastoch et al.

576 (2009b) and Rouault et al. (2009) may reflect an unadjusted oceanic response to the

577 continuously increasing momentum input by the westerlies akin to Stage- 1 . We could

578 further speculate that, should the on-going wind change lessen or halt (Watson et al.

579 2012) in response to stratospheric ozone recovery (Son et al. 2010), future decadal trend

580 in leakage could weaken. This would naturally also depend on the timing and magnitude

581 of the ACC response. It is unclear whether or not the ACC is already eddy saturated

582 (Hallberg and Gnanadesikan 2006; Böning et al. 2008; Spence et al. 2010). We have

583 shown that the circumpolar current plays a relatively critical role in the transient 3-stage

584 leakage response. Therefore, should the ACC be weakly responsive (or unresponsive) to

585 the present-day increasing westerlies, a delay in the onset of a Stage-2-type leakage

586 response can be expected.

587 Rouault et al. (2009) and van Sebille et al. (2009) both related the strength of the

588 Agulhas Current with the magnitude of leakage. Within the present-day range of

589 transport values, they found a linear relationship between the two variables. They did,

590 however, disagree on the sign of that relationship. Results presented here suggest that

591 changes in leakage do not necessitate variations in upstream transport. The Agulhas

592 Current is influenced by both easterlies (Loveday et al. submitted) and westerlies (this 
593 study, Stage-3), while leakage responds predominantly to the westerlies. The

594 disagreement between Rouault et al. (2009) and van Sebille et al. (2009) was most likely

595 an outcome of the different wind field products used in forcing their respective models.

596 In general, within an integral large-scale atmospheric system, statistical relationships

597 between the Agulhas Current and leakage do not necessarily imply cause and impact but

598 instead are manifestations of individual external forcing.

599 Resolution is an important aspect of Agulhas system modeling. The necessity to

600 resolve the Agulhas system adequately has been amply emphasized in the literature (e.g.

601 Biastoch and Krauss 1999; Biastoch et al. 2008c). Beal et al. (2011) even recommend

602 that at least a tenth degree horizontal resolution (e.g. INALT01) is required. Such

603 resolution has not yet been reached by most coupled climate models used for future

604 predictions (Taylor et al. 2012; Weijer et al. 2012). Here, while our series of experiments

605 demonstrate that leakage response to a constant change in westerly winds is represented

606 at all resolutions, we wish to stress the importance in considering the magnitude of the

607 response. For example, a $40 \%$ increase in westerlies during Stage-1 results in

608 approximately the same percentage increase in leakage, which at low-resolution

609 (ORCA05) is $\sim 10 \mathrm{~Sv}$ and at high-resolution (INALT01) is $\sim 6 \mathrm{~Sv}$. Coarse resolution

610 models clearly overestimate the actual volumetric transport and corresponding amount of

611 heat and salt exported into the Atlantic, which ultimately is of critical importance because

612 of the implications for the Atlantic meridional overturning circulation and global climate

613 (Biastoch et al. 2008b,c). Notwithstanding, within the $0.5^{\circ}-0.1^{\circ}$ range, the mechanism

614 behind the response of leakage to changes in the westerlies is consistent. 
615 Our study describes leakage response in the context of changes in the zonal

616 component of westerlies that are constant in time. In reality, the wind system changes

617 progressively and leakage is expected to respond non-linearly to the compounding effects

618 of migrations and magnitudes (deviation from linearity seen in Fig. 12). The meridional

619 component of the wind stress, albeit relatively small on average, may additionally play a

620 role which we have not considered here. Furthermore, changes in the transition zone

621 between the easterlies and westerlies (between $25^{\circ}$ and $35^{\circ} \mathrm{S}$ ) as well as the impact of

622 altered wind forcing on the thermohaline field may also be important.

\section{$6237 . \quad$ Summary}

624 We systematically deconstructed the manner in which the Southern Hemisphere

625 westerlies affect Agulhas leakage and reached the conclusion that the intensity of the

626 wind belt is predominantly responsible in controlling the Indian-Atlantic transport.

627 Agulhas leakage responds rapidly (within $2-3$ years) and proportionally to changes in

628 the westerly wind stress. Change in leakage is comparable to the change in Sverdrup

629 transport across the southern portion of the supergyre. Shifts and modifications to the

630 intensity of the wind belt result in changes in wind energy input that, following Sverdrup

631 dynamics, cause an adjustment of the interior flow. South of Africa, that change is in turn

632 reflected as a change of leakage.

633 Simulations where the intensity of the westerlies was increased show a transient

634 response in leakage. Initially, leakage responds proportionally to the wind increase.

635 Subsequently, after 1 - 2 decades, leakage subsides to normal reference levels. The

636 transient response occurs due to the adjustment of the large-scale circulation. In 
637 particular, energetic interactions between the Antarctic Circumpolar Current and the

638 Agulhas system cause the subsidence in leakage.

639 We also showed that the impact a displacement of the westerly wind belt has on

640 leakage can be regarded as a redistribution of momentum. Shifts of the westerlies

641 equatorward increase the energy input over the southern portion of the supergyre and

642 reduce it over the Southern Ocean. This results in enhanced leakage. Conversely,

643 poleward shifts reduces leakage and the reduction would be accentuated following the

644 adjustment (strengthening) of the circumpolar current. This result is at odds with previous

645 claims.

646 Our investigation further suggested that the process behind the leakage response

647 to changes in the westerlies is independent of model resolution, upstream transport of the

648 Agulhas Current and possibly retroflection energetics. However, this does not discredit

649 the importance of non-linearity in the region. The volumetric change in leakage within

650 models is highly dependent on the correct representation of the numerous non-linear

651 interactions in the Agulhas system. More importantly, the corresponding changes in the

652 amount of heat and salt being exported have the potential of impacting the circulation in

653 the Atlantic.

654

655 Acknowledgments.

656 This work received funding from the European Community's Seventh Framework

657 Programme FP7/2007-2013-Marie-Curie ITN, under grant agreement 238512,

658 GATEWAYS project. Model experiments were performed at the High performance

659 computing centres in Stuttgart (HLRS) and in Cape Town (CHPC) as well as at the 
660 Christian-Albrechts University of Kiel (NESH). The Ariane-v2.2.6 Lagrangian package

661 was used for Agulhas leakage calculation (http://www.univ-brest.fr/lpo/ariane/).

662 Altimetry data for model validation were downloaded from http://aviso.oceanobs.com.

663

664 References

665 Allison, L. C., H. L. Johnson, and D. P. Marshall, 2011: Spin-up and adjustment of the 666 Antarctic Circumpolar Current and global pycnocline. J. Mar. Res., 69, 167-189, 667 doi:10.1357/002224011798765330.

668 Anderson, R. F., Z. Chase, M. Q. Fleisher, and J. Sachs, 2002: The Southern Ocean's 669 biological pump during the Last Glacial Maximum. Deep-Sea Res. II, 49, 19091938, doi:10.1016/S0967-0645(02)00018-8.

Ansorge, I., S. Speich, J. R. E. Lutjeharms, G. J. Goni, C. J. de W. Rautenbach, P. Froneman, M. Rouault, and S. L. Garzoli, 2005: Monitoring the oceanic flow between Africa and Antarctica: Report of the first GoodHope cruise. S. Afr. J. Sci., 101, 29-35.

Arakawa, A., and Y.-J. G. Hsu, 1990: Energy conserving and potential-enstrophy dissipating schemes for the shallow water equations. Mon. Wea. Rev., 118, 1960-

678 Bard, E., and R. E. M. Rickaby, 2009: Migration of the subtropical front as a modulator 679 of glacial climate. Nature, 460, 380-383, doi:10.1038/nature08189.

680 Barnier, B. and Coauthors, 2006: Impact of partial steps and momentum advection 681 schemes in a global ocean circulation model at eddy-permitting resolution. Ocean 682 Dyn., 56, 543-567, doi:10.1007/s10236-006-0082-1. 
683 Beal, L. M., W. P. M. de Ruijter, A. Biastoch, R. Zahn, and SCOR/WCRP/IAPSO-

684 Working-Group-136, 2011: On the role of the Agulhas system in ocean circulation and climate. Nature, 472, 429-436, doi:10.1038/nature09983.

686 Biastoch, A., and W. Krauss, 1999: The Role of Mesoscale Eddies in the Source Regions 687 of the Agulhas Current. J. Phys. Oceanogr., 29, 2303-2317.

688 Biastoch, A., C. W. Böning, J. Getzlaff, J.-M. Molines, and G. Madec, 2008a: Causes of 689 Interannual-Decadal Variability in the Meridional Overturning Circulation of the doi:10.1175/2008JCLI2404.1.

692
Biastoch, A., C. W. Böning, and J. R. E. Lutjeharms, 2008b: Agulhas leakage dynamics affects decadal variability in Atlantic overturning circulation. Nature, 456, 489492, doi:10.1038/nature07426.

Biastoch, A., J. R. E. Lutjeharms, C. W. Böning, and M. Scheinert, 2008c: Mesoscale perturbations control inter-ocean exchange south of Africa. Geophys. Res. Lett., 35, L20602, doi:10.1029/2008GL035132.

Biastoch, A., C. W. Böning, F. U. Schwarzkopf, and J. R. E. Lutjeharms, 2009a: Increase in Agulhas leakage due to poleward shift of Southern Hemisphere westerlies. Nature, 462, 495-498, doi:10.1038/nature08519.

Biastoch, A., L. M. Beal, J. R. E. Lutjeharms, and T. G. D. Casal, 2009b: Variability and Coherence of the Agulhas Undercurrent in a High-Resolution Ocean General Circulation Model. J. Phys. Oceanogr., 39, 2417-2435, doi:10.1175/2009JPO4184.1. 
705 Biastoch, A., and C. W. Böning, 2013: Anthropogenic Impact on Agulhas Leakage.

706

707

708

709

710

711

712

713

714

715

716

717

718

719

720

721

722

723

724

725

726 Geophys. Res. Lett., 40, 1-6, doi:10.1002/grl.50243.

Blanke, B., and P. Delecluse, 1993: Variability of the tropical Atlantic Ocean simulated by a general circulation model with two different mixed-layer physics. J. Phys. Oceanogr., 23, 1363-1388.

Boebel, O., J. Lutjeharms, C. Schmid, W. Zenk, T. Rossby, and C. Barron, 2003: The Cape Cauldron: a regime of turbulent inter-ocean exchange. Deep-Sea Res. II, 50, $57-86$.

Böning, C. W., A. Dispert, M. Visbeck, S. R. Rintoul, and F. U. Schwarzkopf, 2008: The response of the Antarctic Circumpolar Current to recent climate change. Nature Geosci., 1, 864-869, doi:10.1038/ngeo362.

Caley, T., J. Giraudeau, B. Malaizé, L. Rossignol, and C. Pierre, 2012: Agulhas leakage as a key process in the modes of Quaternary climate changes. P. Natl. Acad. Sci. USA, 109, 6835-6839, doi:10.1073/pnas.1115545109.

Chelton, D. B., R. A. DeSzoeke, M. G. Schlax, E. N. Karim, and S. Nicolas, 1998: Geographical variability of the first baroclinic Rossby radius of deformation. $J$. Phys. Oceanogr., 28, $433-460$.

Cunningham, S. A., and R. Marsh, 2010: Observing and modeling changes in the Atlantic MOC. Wiley Interdisciplinary Reviews: Climate Change, 1, 180-191, doi:10.1002/wcc. 22 .

de Ruijter, W. P. M., A. Biastoch, S. S. Drijfhout, J. R. E. Lutjeharms, R. P. Matano, T. Pichevin, P. J. van Leeuwen, and W. Weijer, 1999: Indian-Atlantic interocean 

Dynamics, estimation and impact ring shedding. J. Geophys. Res., 104, 20885 -

$728 \quad 20910$.

729 Debreu, L., and E. Blayo, 2008: Two-way embedding algorithms: a review. Ocean Dyn.,

$730 \quad 58,415-428$, doi:10.1007/s10236-008-0150-9.

731 Dencausse, G., M. Arhan, and S. Speich, 2010: Spatio-temporal characteristics of the 732 Agulhas Current retroflection. Deep-Sea Res. I, 57, 1392-1405, 733 doi:10.1016/j.dsr.2010.07.004.

734 Dijkstra, H. A., and W. P. M. de Ruijter, 2001: On the Physics of the Agulhas Current: 735 Steady Retroflection Regimes. J. Phys. Oceanogr., 31, 2971-2985.

736 Downes, S. M., a. S. Budnick, J. L. Sarmiento, and R. Farneti, 2011: Impacts of wind 737 stress on the Antarctic Circumpolar Current fronts and associated subduction. 738 Geophys. Res. Lett., 38, 3-8, doi:10.1029/2011GL047668.

739 Franzese, A., S. Hemming, S. Goldstein, and R. Anderson, 2006: Reduced Agulhas

740 Leakage during the Last Glacial Maximum inferred from an integrated

741 provenance and flux study. Earth Planet. Sci. Lett., 250, 72-88, 742 doi:10.1016/j.epsl.2006.07.002.

743 Franzese, A. M., S. R. Hemming, and S. L. Goldstein, 2009: Use of strontium isotopes in 744 detrital sediments to constrain the glacial position of the Agulhas Retroflection.

745 Paleoceanography, 24, PA2217, doi:10.1029/2008PA001706.

746 Fyfe, J. C., and O. A. Saenko, 2006: Simulated changes in the extratropical Southern

$747 \quad$ Hemisphere winds and currents. Geophys. Res. Lett., 33, L06701,

748 doi:10.1029/2005GL025332. 
749 Fyfe, J. C., O. A. Saenko, K. Zickfeld, M. Eby, and A. J. Weaver, 2007: The Role of

750 Poleward-Intensifying Winds on Southern Ocean Warming. J. Climate, 20, 5391$751 \quad 5400$, doi:10.1175/2007JCLI1764.1.

752 Gent, P. R., and J. C. McWilliams, 1990: Isopycnal Mixing in Ocean Circulation Models. $753 \quad$ J. Phys. Oceanogr., 20, 150-155.

754 Gordon, A. L., 1986: Interocean exchange of Thermocline Water. J. Geophys. Res., 91 , $755 \quad$ 5037-5046, doi:10.1029/JC091iC04p05037.

756 Gordon, A. L., R. F. Weiss, W. M. Smethie, and M. J. Warner, 1992: Thermocline and 757 Intermediate Water Communication between the South Atlantic and Indian $758 \quad$ Oceans. J. Geophys. Res., 97, 7223-7240.

759 Graham, R. M., A. M. de Boer, K. J. Heywood, M. R. Chapman, and D. P. Stevens, 760 2012: Southern Ocean fronts: Controlled by wind or topography? J. Geophys. Res., 117, 1-14, doi:10.1029/2012JC007887.

762 Haidvogel, D. B., and A. Beckmann, 1999: Numerical Ocean Circulation Modeling. 763 Series on Environmental Science and Management: Volume 2, 344pp.

764 Hallberg, R., and A. Gnanadesikan, 2006: The Role of Eddies in Determining the 765 Structure and Response of the Wind-Driven Southern Hemisphere Overturning:

766 Results from the Modeling Eddies in the Southern Ocean (MESO) Project. $J$. 767 Phys. Oceanogr., 36, 2232-2252, doi:10.1175/JPO2980.1.

768 Hodgson, D. a., and L. C. Sime, 2010: Palaeoclimate: Southern westerlies and CO2. 769 Nature Geosci., 3, 666-667, doi:10.1038/ngeo970. 
770 Knorr, G., and G. Lohmann, 2003: Southern Ocean origin for the resumption of Atlantic

771 thermohaline circulation during deglaciation. Nature, 424, 532-536,

772 doi:10.1038/nature01855.

773 Kohfeld, K.E., R. M. Graham, A. M. de Boer, L. C. Sime, E. W. Wolff, C. Le Quéré, and

774 L. Bopp, 2013: Southern Hemisphere westerly wind changes during the Last

775 Glacial Maximum: paleo-data synthesis. Quat. Sci. Rev, , 68, 76-95,

776 doi:10.1016/j.quascirev.2013.01.017.

777 Large, W. G., J. C. Mcwilliams, and S. C. Doney, 1994: Oceanic vertical mixing: A

778 review and a model with a nonlocal boundary layer parameterization. Rev.

779 Geophys., 32, 363-403.

780 Large, W. G., and S. G. Yeager, 2009: The global climatology of an interannually

781 varying air-sea flux data set. Climate Dyn., 33, 341-364, doi:10.1007/s00382-

$782 \quad 008-0441-3$.

783 Le Bars, D., W. P. M. de Ruijter, and H. A. Dijkstra, 2012: A New Regime of the

784 Agulhas Current Retroflection: Turbulent Choking of Indian-Atlantic leakage. $J$.

785 Phys. Oceanogr., 42, 1158-1172, doi:10.1175/JPO-D-11-0119.1.

786 Loveday, B. R., J. V. Durgadoo, C. J. C. Reason, A. Biastoch, and P. Penven, Decoupling

787 of the Agulhas Current from the Agulhas Leakage. J. Phys. Oceanogr., submitted.

788 Madec, G., 2008: NEMO ocean engine. Note du Pole de modeisation de l'Institut Pierre-

789 Simon Laplace No 27, ISSN No 12, 215pp.

790 Madec, G., and M. Imbard, 1996: A global ocean mesh to overcome the North Pole

791 singularity. Climate Dyn., 12, 381-388, doi:10.1007/BF00211684. 
792 Marchesiello, P., J. C. McWilliams, and A. Shchepetkin, 2001: Open boundary

793 conditions for long-term integration of regional oceanic models. Ocean Modell.,

$794 \quad 3,1-20$, doi:10.1016/S1463-5003(00)00013-5.

795 Marchesiello, P., L. Debreu, and X. Couvelard, 2009: Spurious diapycnal mixing in

796 terrain-following coordinate models: The problem and a solution. Ocean Modell.,

$797 \quad 26,156-169$, doi:10.1016/j.ocemod.2008.09.004.

798 Marshall, J., and R. Plumb, 2007: Atmosphere, ocean and climate dynamics: an

799 introductory text. Academic Press, 334pp.

800 Meredith, M. P. and Coauthors, 2011: Sustained monitoring of the Southern Ocean at

801 Drake Passage: Past achievements and future priorities. Rev. Geophys., 49,

$802 \quad$ RG4005, doi:10.1029/2010RG000348.

803 Oke, P., and M. England, 2004: Oceanic response to changes in the latitude of the

804 Southern Hemisphere subpolar westerly winds. J. Climate, 17, 1040-1054.

805 Otto-Bliesner, B. L., E. C. Brady, G. Clauzet, R. Tomas, S. Levis, and Z. Kothavala,

806 2006: Last Glacial Maximum and Holocene Climate in CCSM3. J. Climate, 19,

$807 \quad 2526-2544$, doi:10.1175/JCLI3748.1.

808 Ou, H., and W. de Ruijter, 1986: Separation of an inertial boundary current from a curved

809 coastline. J. Phys. Oceanogr., 16, 280-289.

810 Peeters, F. J. C., R. Acheson, G.-J. a Brummer, W. P. M. de Ruijter, R. R. Schneider, G.

811 M. Ganssen, E. Ufkes, and D. Kroon, 2004: Vigorous exchange between the

812 Indian and Atlantic oceans at the end of the past five glacial periods. Nature, 430,

$813 \quad 661-665$, doi:10.1038/nature02785. 
814 Penven, P., J. R. E. Lutjeharms, and P. Florenchie, 2006: Madagascar: A pacemaker for

815 the Agulhas Current system? Geophys. Res. Lett., 33, L17609,

816 doi:10.1029/2006GL026854.

817 Penven, P., P. Marchesiello, L. Debreu, and J. Lefèvre, 2008: Software tools for pre- and 818 post-processing of oceanic regional simulations. Environ. Modell. Softw., 23,

819 660-662, doi:10.1016/j.envsoft.2007.07.004.

820 Pichevin, T., D. Nof, and J. R. E. Lutjeharms, 1999: Why are there Agulhas Rings. J.

$821 \quad$ Phys. Oceanogr., 29, 693-707.

822 Richardson, P. L., 2007: Agulhas leakage into the Atlantic estimated with subsurface

823 floats and surface drifters. Deep-Sea Res. I, 54, 1361-1389,

824 doi:10.1016/j.dsr.2007.04.010.

825 Ridgway, K. R., and J. R. Dunn, 2007: Observational evidence for a Southern

826 Hemisphere oceanic supergyre. Geophys. Res. Lett., 34, L13612,

827 doi:10.1029/2007GL030392.

828 Rojas, M. and Coauthors, 2008: The Southern Westerlies during the last glacial

829 maximum in PMIP2 simulations. Climate Dyn., 32, 525-548,

$830 \quad$ doi:10.1007/s00382-008-0421-7.

831 Rouault, M., P. Penven, and B. Pohl, 2009: Warming in the Agulhas Current system

832 since the 1980's. Geophys. Res. Lett., 36, L12602, doi:10.1029/2009GL037987.

833 Shchepetkin, A. F., and J. C. McWilliams, 1998: Quasi-monotone advection schemes

834 based on explicit locally adaptive dissipation. Mon. Wea. Rev., 126, 1542-1580. 
835 Shchepetkin, A. F., and J. C. McWilliams, 2005: The regional oceanic modeling system

836 (ROMS): a split-explicit, free-surface, topography-following-coordinate oceanic

837 model. Ocean Modell., 9, 347-404, doi:10.1016/j.ocemod.2004.08.002.

838 Sijp, W. P., and M. H. England, 2008: The effect of a northward shift in the southern

839 hemisphere westerlies on the global ocean. Prog. Oceanogr., 79, 1-19,

$840 \quad$ doi:10.1016/j.pocean.2008.07.002.

841 Sijp, W. P., and M. H. England, 2009: Southern Hemisphere Westerly Wind Control over

842 the Ocean's Thermohaline Circulation. J. Climate, 22, 1277-1286,

$843 \quad$ doi:10.1175/2008JCLI2310.1.

844 Smagorinsky, J., 1963: General circulation experiments with the primitive equations. I.

845 The basic experiment. Mon. Wea. Rev., 27, 99-164.

846 Son, S.-W. and Coauthors, 2010: Impact of stratospheric ozone on Southern Hemisphere

847 circulation change: A multimodel assessment. J. Geophys. Res., 115, D00M07, $848 \quad$ doi:10.1029/2010JD014271.

849 Speich, S., B. Blanke, and G. Madec, 2001: Warm and cold water routes of an OGCM

$850 \quad$ thermohaline conveyor belt. Geophys. Res. Lett., 28, 311-314.

851 Spence, P., J. C. Fyfe, A. Montenegro, and A. J. Weaver, 2010: Southern Ocean

852 Response to Strengthening Winds in an Eddy-Permitting Global Climate Model.

$853 \quad$ J. Climate, 23, 5332-5343, doi:10.1175/2010JCLI3098.1.

854 Steele, M., R. Morfley, and W. Ermold, 2001: PHC: A global ocean hydrography with 855 high-quality Artic Ocean. J. Climate, 14, 2079-2087. 
856 Swart, N. C., and J. C. Fyfe, 2012: Observed and simulated changes in the Southern

857 Hemisphere surface westerly wind-stress. Geophys. Res. Lett., 39, 6-11, 858 doi:10.1029/2012GL052810.

859 Taylor, K. E., R. J. Stouffer, and G. A. Meehl, 2012: An Overview of CMIP5 and the 860 Experiment Design. Bull. Amer. Meteor. Soc., 93, 485-498, doi:10.1175/BAMS-

$861 \quad$ D-11-00094.1.

862 The DRAKKAR Group, 2007: Eddy-permitting ocean circulation hindcasts of past 863 decades. CLIVAR Exchanges, Vol. 12 of, 8-14.

864 Toggweiler, J. R., J. L. Russell, and S. R. Carson, 2006: Midlatitude westerlies, 865 atmospheric $\mathrm{CO} 2$, and climate change during the ice ages. Paleoceanography, $866 \quad 21,1-15$, doi:10.1029/2005PA001154.

867 Tréguier A.-M., 1992: Kinetic energy analysis of an eddy resolving, primitive equation $868 \quad$ North Atlantic model. J. Geophys. Res., 97, 687-701.

869 van Sebille, E., A. Biastoch, P. J. van Leeuwen, and W. P. M. de Ruijter, 2009: A weaker 870 Agulhas Current leads to more Agulhas leakage. Geophys. Res. Lett., 36, L03601, 871 doi:10.1029/2008GL036614.

872 van Sebille, E., and P. J. van Leeuwen, 2007: Fast northward energy transfer in the 873 Atlantic due to Agulhas rings. J. Phys. Oceanogr., 37, 2305-2315, 874 doi:10.1175/JPO3108.1.

875 van Sebille, E., P. J. van Leeuwen, A. Biastoch, and W. P. M. de Ruijter, 2010: Flux 876 comparison of Eulerian and Lagrangian estimates of Agulhas leakage: A case 877 study using a numerical model. Deep-Sea Res. I, 57, 319-327, $878 \quad$ doi:10.1016/j.dsr.2009.12.006. 
879 Watson, P. a. G., D. J. Karoly, M. R. Allen, N. Faull, and D. S. Lee, 2012: Quantifying 880 uncertainty in future Southern Hemisphere circulation trends. Geophys. Res. Lett., $881 \quad 39$, L23708, doi:10.1029/2012GL054158.

882 Weijer, W. and Coauthors, 2012: The Southern Ocean and Its Climate in CCSM4. J. 883 Climate, 25, 2652-2675, doi:10.1175/JCLI-D-11-00302.1.

884 Wyrwoll, K.-H., B. Dong, and P. Valdes, 2000: On the position of southern hemisphere 885 westerlies at the Last Glacial Maximum: an outline of AGCM simulation results 886 and evaluation of their implications. Quat. Sci. Rev., 19, 881-898, 887 doi:10.1016/S0277-3791(99)00047-5.

888 Zahn, R., J. R. E. Lutjeharms, A. Biastoch, G. Knorr, W. Park, C. J. C. Reason, 2010:

889 Investigating the Global Impacts of the Agulhas Current. Eos. Trans. AGU, 91, $890 \quad 109-110$.

891 Zalesak, S. T., 1979: Fully multidimensional flux corrected transport algorithms for 892 fluids. J. Comput. Phys., 31, 335-362.

893 


\section{List of Figures}

896 FIG. 1. Mid-depth $(250-400 \mathrm{~m})$ temperature (shading, $\left.{ }^{\circ} \mathrm{C}\right)$ and velocity gradients (shown

897 as the 3-dimentional-depth expression), 5-day average snapshot centered at 17 Jun 2006

898 from the hind-cast realization of INALT01 illustrating the major pathway of Agulhas

899 leakage across the South Atlantic. The INALT01 configuration consists of a global half-

900 degree model with a tenth-degree nest over the region demarked by the grey box $\left(50^{\circ} \mathrm{S}-\right.$

$\left.9018^{\circ} \mathrm{N}, 70^{\circ} \mathrm{W}-70^{\circ} \mathrm{E}\right)$.

902

903 FIG. 2. Volume integrated $\left(10^{\circ} \mathrm{W}-60^{\circ} \mathrm{E} ; 10^{\circ}-45^{\circ} \mathrm{S}\right)$ kinetic energy per unit mass $\left(\mathrm{m}^{2} \mathrm{~s}\right.$

$904^{2}$ ) with annual values (thick lines) overlaying monthly values (grey). Following a 20 year

905 spin-up, reference (REF, black lines) experiments were performed for all three models.

906 Wind anomalies were added from year 31; example of the SHW+40\% (red lines) runs is

907 shown. For the purpose of clarity, INALT01 values are offset by $1 \times 10^{20} \mathrm{~m}^{2} \mathrm{~s}^{-2}$.

908 Common analysis period (model years $51-60$ ) for Fig. 6 is indicated by the blue

909 shading.

910

911 FIG. 3. (a) Wind stress magnitude (shading, $\mathrm{N} \mathrm{m}^{-2}$ ) and direction (vector) with horizontal

912 barotropic stream-function contours overlay (data extracted from ORCA05-REF

913 experiment); contour interval at 10 and $25 \mathrm{~Sv}$ for negative (dashed line) and positive (full

914 lines) values respectively, thick contour represent the zero-line. (b) and (c) Zonally

915 averaged $\left(20^{\circ}-115^{\circ} \mathrm{E}\right)$ wind-stress $\left(\mathrm{N} \mathrm{m}^{-2}\right)$ with thick black curve indicating the time-

916 reference case. (b) Westerly position altered by $-4^{\circ}$ (blue), $-2^{\circ}$ (green), $+2^{\circ}$ (pink) and $+4^{\circ}$

917 (red) about the mean (black), without changing the total energy input. (c) Intensity 
918 change by $-40 \%$ (blue), $-20 \%$ (green), $+20 \%$ (pink), and $+40 \%$ (red) of the mean

919 (black). Wind changes are applied within the region $35^{\circ}-63^{\circ} \mathrm{S}$.

920

921 FIG. 4. Application of the SHW+40\% anomaly (40\% intensification of westerlies). The

922 wind stress anomaly $\left(\mathrm{N} \mathrm{m}^{-2}\right)$ is applied (a) circumpolarly (FULL); (b) circumpolarly

923 except the region bounded by $0^{\circ}-35^{\circ} \mathrm{E}$, north of $45^{\circ} \mathrm{S}$ (BASIN); (c) only over the region

924 bounded by $0^{\circ}-35^{\circ} \mathrm{E}$, north of $45^{\circ} \mathrm{S}$ (LOCAL); (d) over region west of $18^{\circ} \mathrm{E}$ and east of

$925115^{\circ} \mathrm{E}(\mathrm{ACC}-\mathrm{P}) ;(\mathrm{e})$ between region $18^{\circ} \mathrm{W}-115^{\circ} \mathrm{E}(\mathrm{ACC}-\mathrm{B})$; and (f) between region $0^{\circ}-$ $92635^{\circ} \mathrm{E}(\mathrm{ACC}-\mathrm{L})$.

927

928 FIG. 5. Representation of mean circulation (contours of sea surface height (SSH)

929 averaged for period 1992 - 2007) and mesoscale variability (shading of SSH variance,

$930 \mathrm{~cm}^{2}$ ) from (a) altimetric observation AVISO, (b) ORCA05, (c) AGIO and (d) INALT01.

931 Sections used to measure Agulhas leakage across the Good-Hope Line (GH), the Agulhas

932 Current (AC), the Mozambique throughflow (Moz) and the region where the Agulhas

933 Return Current is monitored (box) are shown in (b). The domain used for the Lagrangian

934 analysis is shown in (d).

935

936 FIG. 6. Change in Agulhas leakage (\%) versus change in (a) position ( ${ }^{\circ}$ Lat) and (b \& c)

937 intensity (\%) of the Southern Hemisphere westerlies (SHW). Reference values (black

938 dot) are set at the origin for all three models and each dot represents a decade average

939 (model years 51 - 60, blue shading in Fig. 2). (c) The decomposition between FULL, 
940 BASIN and LOCAL is shown for the SHW-40\% and SHW+40\% cases. The gray line in

941 b \& c represent the theoretical change in Sverdrup transport.

942

943 FIG. 7. Time-series for the REF and SHW+40\% cases within ORCA05. Sections used to

944 measure the transports are shown in Fig. 5a and aside from the Agulhas leakage (AL), all

945 transports are measured from the barotropic stream-function: the Antarctic Circumpolar

946 Current (ACC) as the maximum stream-function south of Africa between $20^{\circ}$ and $30^{\circ} \mathrm{E}$;

947 the sub-gyre strength as the minimum stream-function value between $30^{\circ}$ and $60^{\circ} \mathrm{E}$; the

948 Agulhas Current (AC) as the minimum stream-function along the section at $32^{\circ} \mathrm{S}$. For the

949 Agulhas Return Current (ARC), speed is for the top $1000 \mathrm{~m}$. The light red, yellow and

950 blue shadings indicate Stage-1, Stage-2 and Stage-3 in ORCA05-SHW+40\%-FULL

951 leakage response respectively (details in text).

952

953 FIG. 8. Same as Fig. 7 for INALT01.

954

955 FIG. 9. Time-series of Agulhas leakage (AL), Agulhas Return Current variance (ARC

956 Var) and Antarctic Circumpolar Current (ACC) transport from the ACC-P (pink), ACC-B

957 (blue) and ACC-L (green) decompositions of the SHW+40\% anomaly within ORCA05.

958 The light red, yellow and blue shadings indicate Stage-1, Stage-2 and Stage-3 in

959 ORCA05-SHW+40\%-FULL leakage response respectively (extracted from Fig. 7).

960

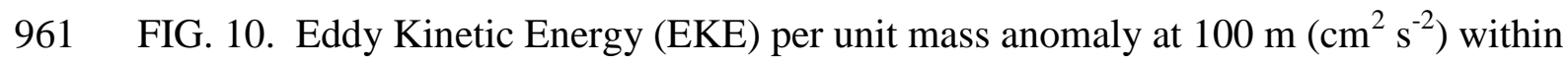

962 ORCA05 (left) and INALT01 (right) averaged over model years 41 - 45 (a \& c) and 56 - 
96360 (b \& d). Contours indicate the respective averaged reference EKE values for model

964 years $41-60$.

965

966 FIG. 11. Schematic of the proposed mechanism of leakage response to the westerlies.

967 Contours of barotropic stream function portray the anticyclonic supergyre (shaded area)

968 connecting the South Indian and South Atlantic oceans, with thick black contour

969 demarcating its boundaries (data extracted from ORCA05-REF experiment). Thick

970 arrows indicate the meridional Sverdrup interior flow and the corresponding zonal

971 transport that results from the wind stress application (REF in black and SHW+40\% case

972 in red). The circulation is closed by the return flow of the western boundary currents

973 (dotted arrows).

974

975 FIG. 12. Change in Agulhas leakage (\%) versus change in wind stress (\%) averaged over

976 the region $20^{\circ} \mathrm{W}-140^{\circ} \mathrm{E}, 35^{\circ}-65^{\circ} \mathrm{S}$. Squares represent decadal averages from hind-cast

977 inter-annual (IA) simulations of ORCA05-IA (light blue) and INALT01-IA (light green),

978 with the period 1964-1973 taken as reference (set at origin); Circles represent Stage-1

979 averages (model years 41-45) from the FULL application of the SHW+20\% and

980 SHW +40\% anomalies as well as the corresponding REF (set at origin) within ORCA05

981 (blue) and INALT01 (green). 
982 TABLE 1. Sensitivity experiments and their integration periods (in years). IA: Inter-

983 Annual; REF: Reference; SHW: Southern Hemisphere westerlies. Domain

984 decompositions are depicted in Fig. 4.

\begin{tabular}{|c|c|c|c|c|c|}
\hline \multirow{2}{*}{ Experiment } & \multirow{2}{*}{ Domain } & \multirow{2}{*}{ Description } & \multicolumn{3}{|c|}{ Model Configurations } \\
\hline & & & ORCA05 & $\mathrm{AGIO}$ & INALT01 \\
\hline IA & $\mathrm{n} / \mathrm{a}$ & Inter-annual Reference & $1948-2007$ & & $1948-2007$ \\
\hline REF & $\mathrm{n} / \mathrm{a}$ & Climatological Reference & $1-110$ & $1-60$ & $1-60$ \\
\hline $\mathrm{SHW}+4$ & FULL & $4^{\circ}$ Equatorward shift & $31-60$ & & $31-60$ \\
\hline $\mathrm{SHW}+2$ & FULL & $2^{\circ}$ Equatorward shift & $31-60$ & & \\
\hline SHW-2 & FULL & $2^{\circ}$ Poleward shift & $31-60$ & & $31-60$ \\
\hline SHW-4 & FULL & $4^{\circ}$ Poleward shift & $31-60$ & & \\
\hline \multirow{3}{*}{ SHW-40\% } & FULL & \multirow{3}{*}{$40 \%$ Intensity decrease } & $31-110$ & $31-60$ & $31-60$ \\
\hline & BASIN & & $31-60$ & & \\
\hline & LOCAL & & $31-60$ & & \\
\hline SHW-20\% & FULL & $20 \%$ Intensity decrease & $31-60$ & $31-60$ & \\
\hline $\mathrm{SHW}+20 \%$ & FULL & $20 \%$ Intensity increase & $31-60$ & $31-60$ & \\
\hline \multirow{7}{*}{$\mathrm{SHW}+40 \%$} & FULL & \multirow{6}{*}{$40 \%$ Intensity increase } & $31-110$ & $31-60$ & $31-60$ \\
\hline & BASIN & & $31-80$ & & \\
\hline & LOCAL & & $31-80$ & & $31-60$ \\
\hline & ACC-P & & $31-60$ & & \\
\hline & ACC-B & & $31-60$ & & \\
\hline & ACC-L & & $31-60$ & & \\
\hline & $\mathrm{ACC}$ & AGIO boundary condition ${ }^{*}$ & $\mathrm{n} / \mathrm{a}$ & $31-60$ & $\mathrm{n} / \mathrm{a}$ \\
\hline
\end{tabular}

985 *Further details in text.

986

987 


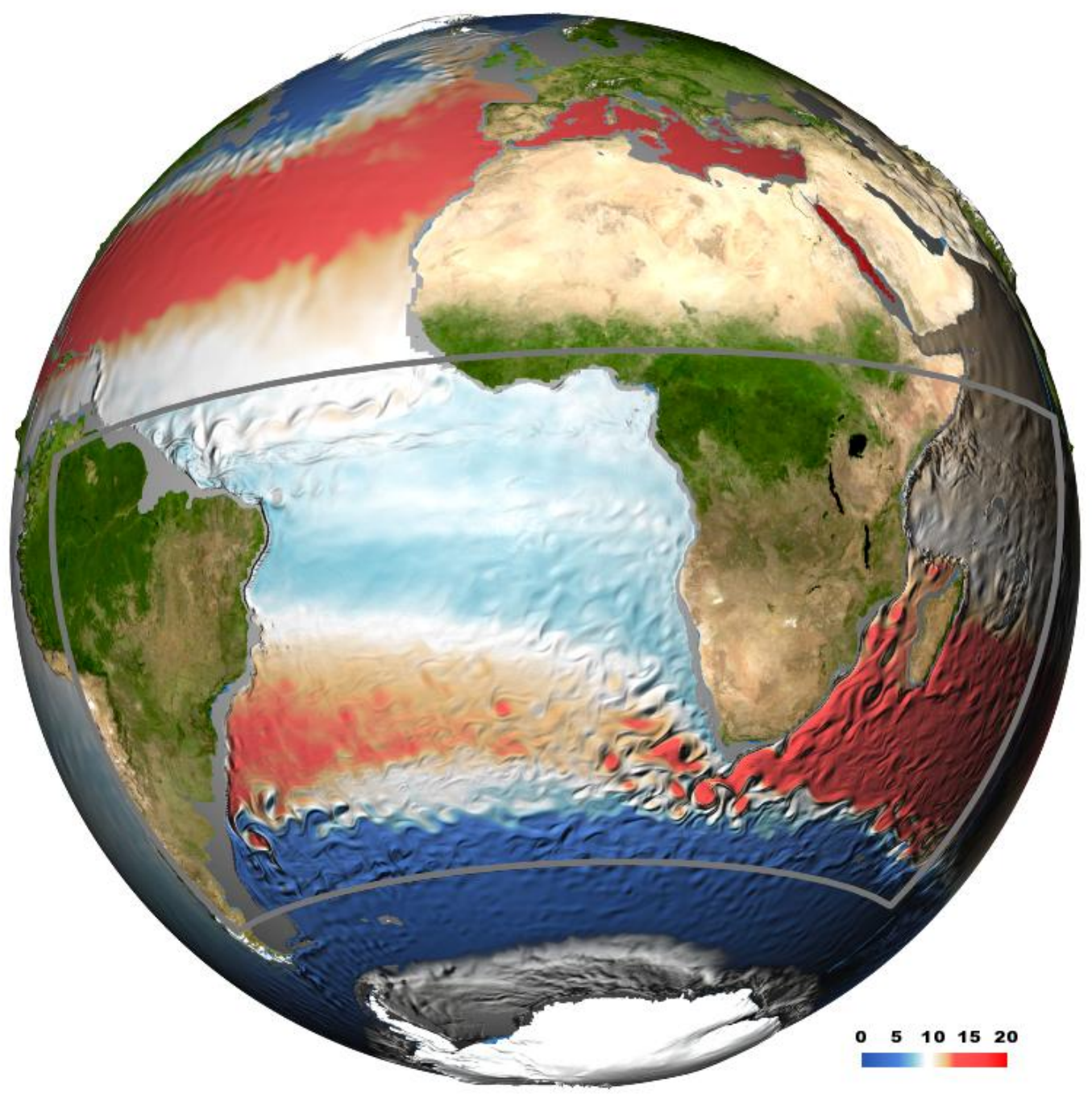

989

990 FIG. 1. Mid-depth $(250-400 \mathrm{~m})$ temperature (shading, $\left.{ }^{\circ} \mathrm{C}\right)$ and velocity gradients (shown

991 as the 3-dimentional-depth expression), 5-day average snapshot centered at 17 Jun 2006

992 from the hind-cast realization of INALT01 illustrating the major pathway of Agulhas

993 leakage across the South Atlantic. The INALT01 configuration consists of a global half-

994 degree model with a tenth-degree nest over the region demarked by the grey box $\left(50^{\circ} \mathrm{S}-\right.$

$\left.9958^{\circ} \mathrm{N}, 70^{\circ} \mathrm{W}-70^{\circ} \mathrm{E}\right)$. 


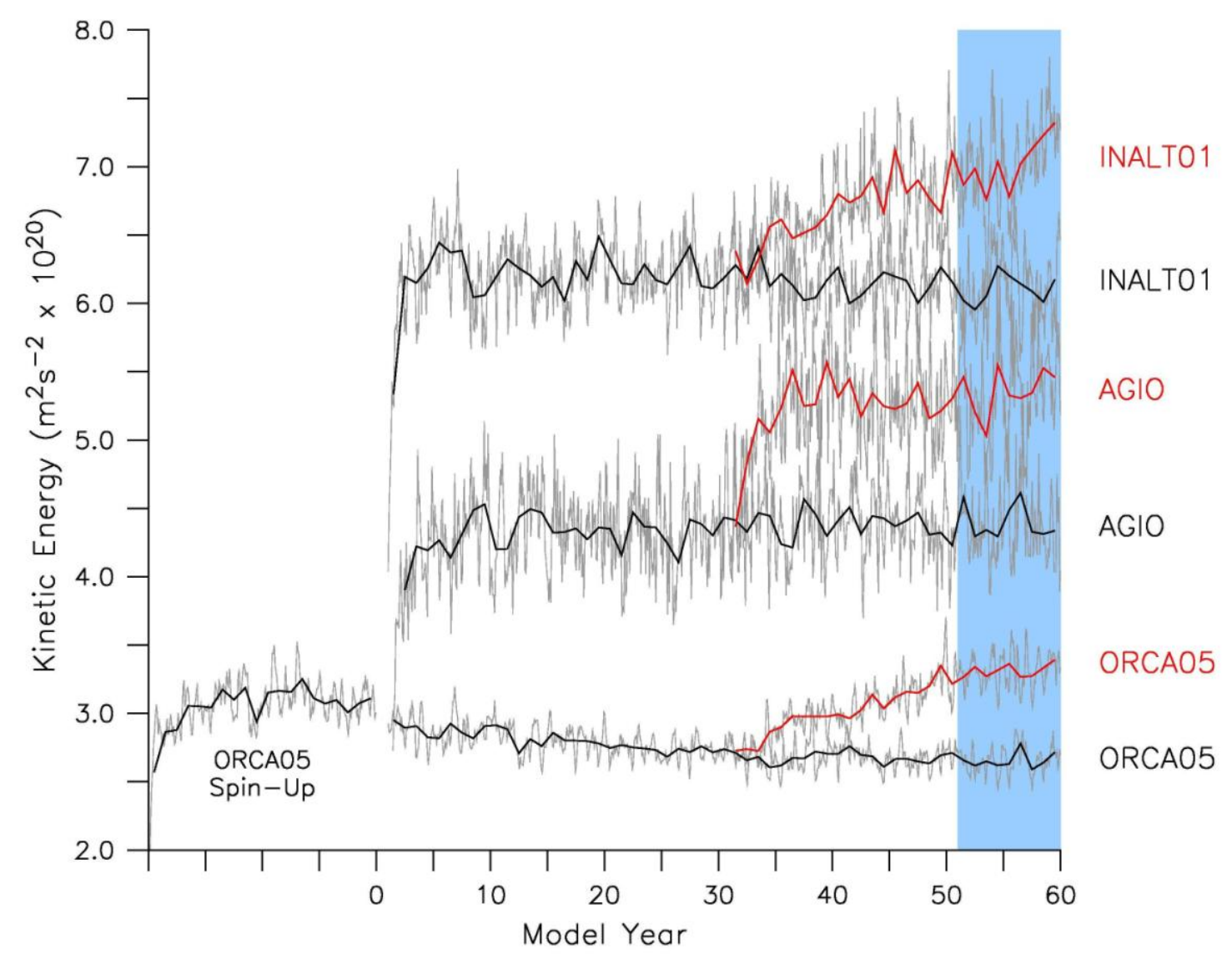

998

999 FIG. 2. Volume integrated $\left(10^{\circ} \mathrm{W}-60^{\circ} \mathrm{E} ; 10^{\circ}-45^{\circ} \mathrm{S}\right)$ kinetic energy per unit mass $\left(\mathrm{m}^{2} \mathrm{~s}^{-}\right.$

$100{ }^{2}$ ) with annual values (thick lines) overlaying monthly values (grey). Following a 20 year

1001 spin-up, reference (REF, black lines) experiments were performed for all three models.

1002 Wind anomalies were added from year 31; example of the SHW+40\% (red lines) runs is

1003 shown. For the purpose of clarity, INALT01 values are offset by $1 \times 10^{20} \mathrm{~m}^{2} \mathrm{~s}^{-2}$.

1004 Common analysis period (model years $51-60$ ) for Fig. 6 is indicated by the blue 1005 shading. 


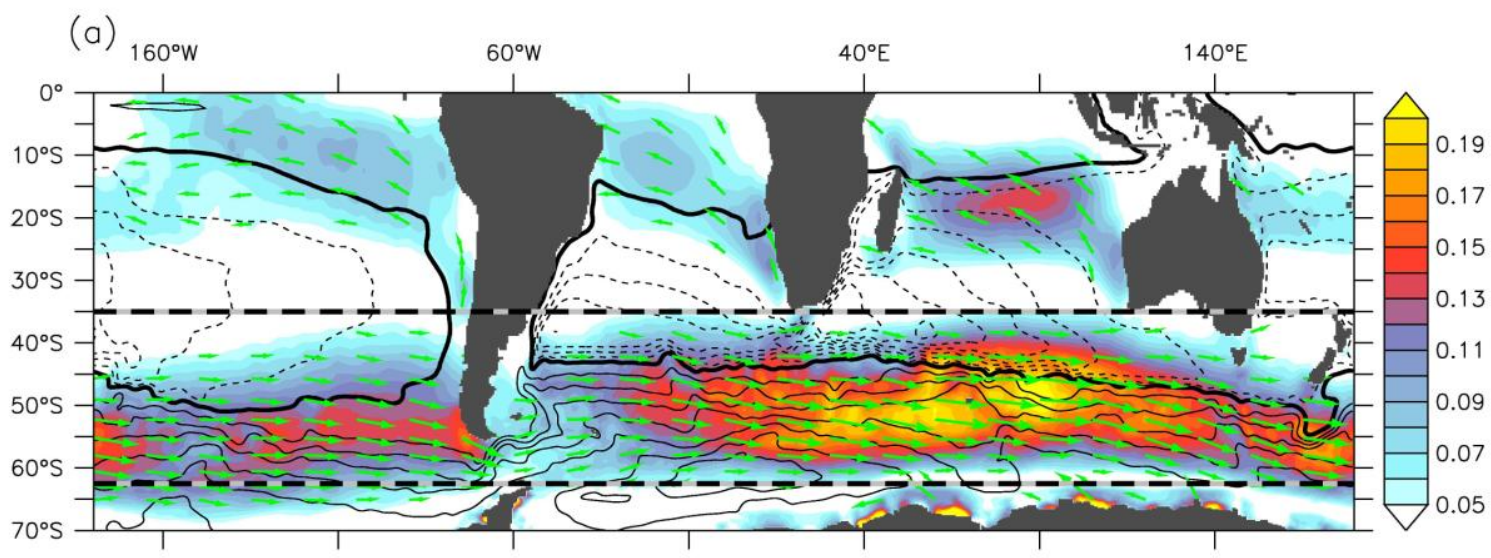

(b)

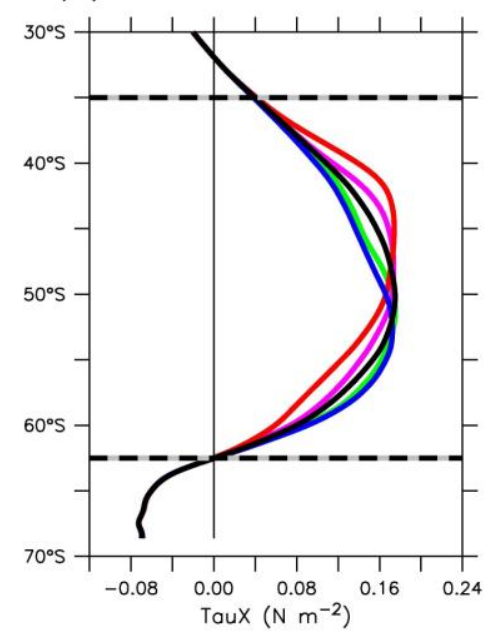

(c)

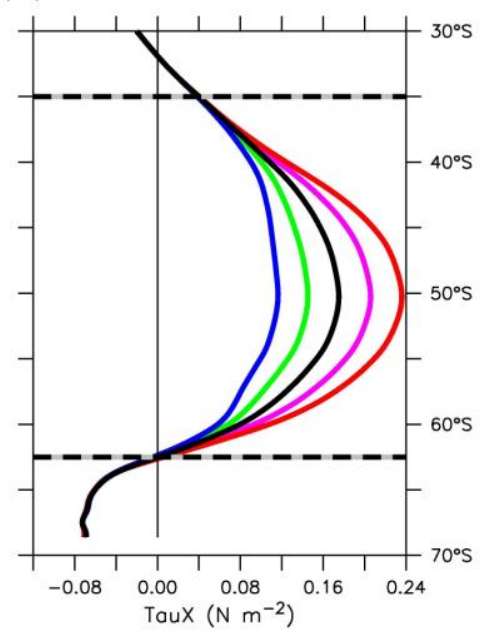

FIG. 3. (a) Wind stress magnitude (shading, $\mathrm{N} \mathrm{m}^{-2}$ ) and direction (vector) with horizontal

1010 barotropic stream-function contours overlay (data extracted from ORCA05-REF

1011 experiment); contour interval at 10 and $25 \mathrm{~Sv}$ for negative (dashed line) and positive (full

1012 lines) values respectively, thick contour represent the zero-line. (b) and (c) Zonally

1013 averaged $\left(20^{\circ}-115^{\circ} \mathrm{E}\right)$ wind-stress $\left(\mathrm{N} \mathrm{m}^{-2}\right)$ with thick black curve indicating the time-

1014 reference case. (b) Westerly position altered by $-4^{\circ}$ (blue), $-2^{\circ}$ (green), $+2^{\circ}$ (pink) and $+4^{\circ}$

1015 (red) about the mean (black), without changing the total energy input. (c) Intensity

1016 change by $-40 \%$ (blue), $-20 \%$ (green), $+20 \%$ (pink), and $+40 \%$ (red) of the mean

1017 (black). Wind changes are applied within the region $35^{\circ}-63^{\circ} \mathrm{S}$. 
1018

1019
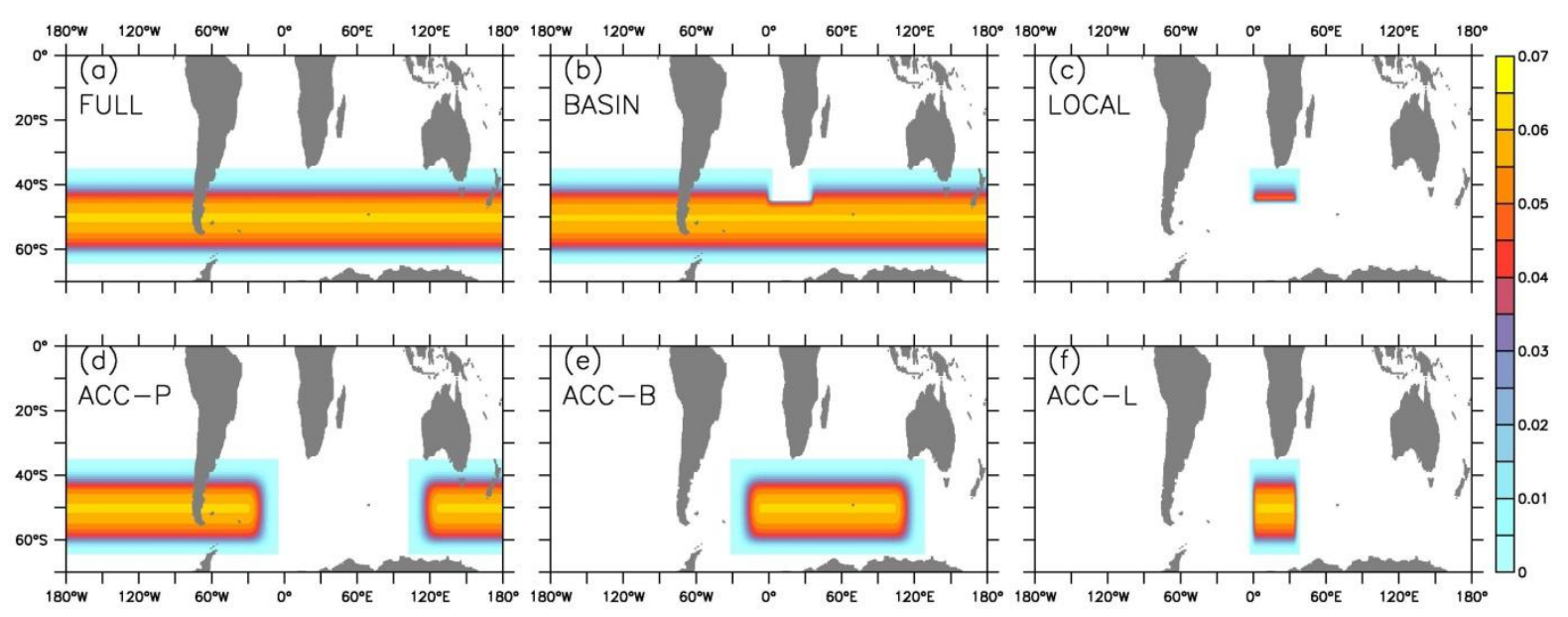

1020 FIG. 4. Application of the SHW+40\% anomaly (40\% intensification of westerlies). The

1021 wind stress anomaly $\left(\mathrm{N} \mathrm{m}^{-2}\right)$ is applied (a) circumpolarly (FULL); (b) circumpolarly

1022 except the region bounded by $0^{\circ}-35^{\circ} \mathrm{E}$, north of $45^{\circ} \mathrm{S}$ (BASIN); (c) only over the region

1023 bounded by $0^{\circ}-35^{\circ} \mathrm{E}$, north of $45^{\circ} \mathrm{S}$ (LOCAL); (d) over region west of $18^{\circ} \mathrm{E}$ and east of

$1024115^{\circ} \mathrm{E}(\mathrm{ACC}-\mathrm{P}) ;(\mathrm{e})$ between region $18^{\circ} \mathrm{W}-115^{\circ} \mathrm{E}(\mathrm{ACC}-\mathrm{B})$; and (f) between region $0^{\circ}-$

$102535^{\circ} \mathrm{E}(\mathrm{ACC}-\mathrm{L})$.

1026

1027

1028 

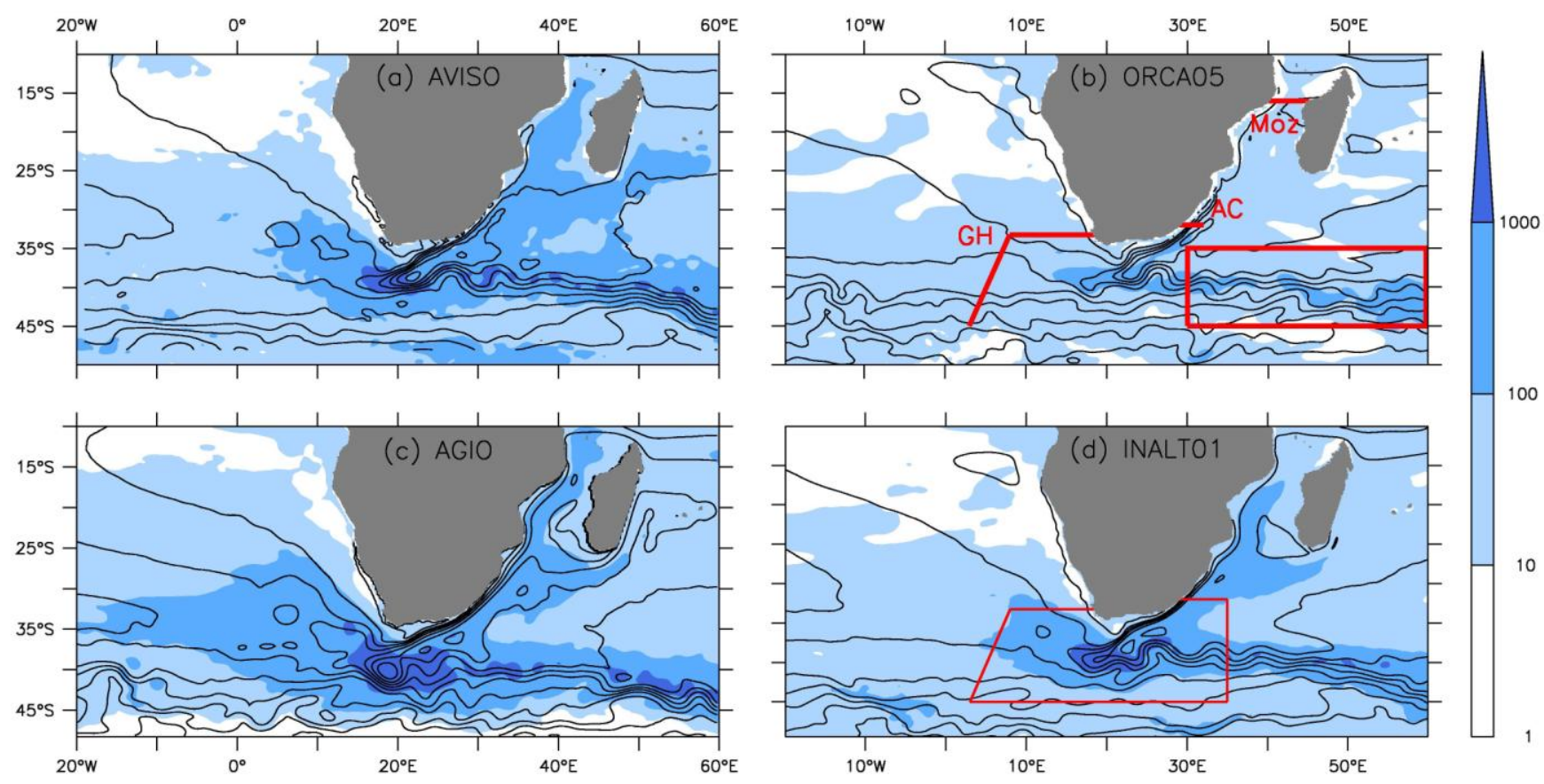

FIG. 5. Representation of mean circulation (contours of sea surface height (SSH)

1032 averaged for period 1992 - 2007) and mesoscale variability (shading of SSH variance,

$1033 \mathrm{~cm}^{2}$ ) from (a) altimetric observation AVISO, (b) ORCA05, (c) AGIO and (d) INALT01.

1034 Sections used to measure Agulhas leakage across the Good-Hope Line (GH), the Agulhas

1035 Current (AC), the Mozambique throughflow (Moz) and the region where the Agulhas

1036 Return Current is monitored (box) are shown in (b). The domain used for the Lagrangian

1037 analysis is shown in (d).

1038

1039 
(a) SHW - Position

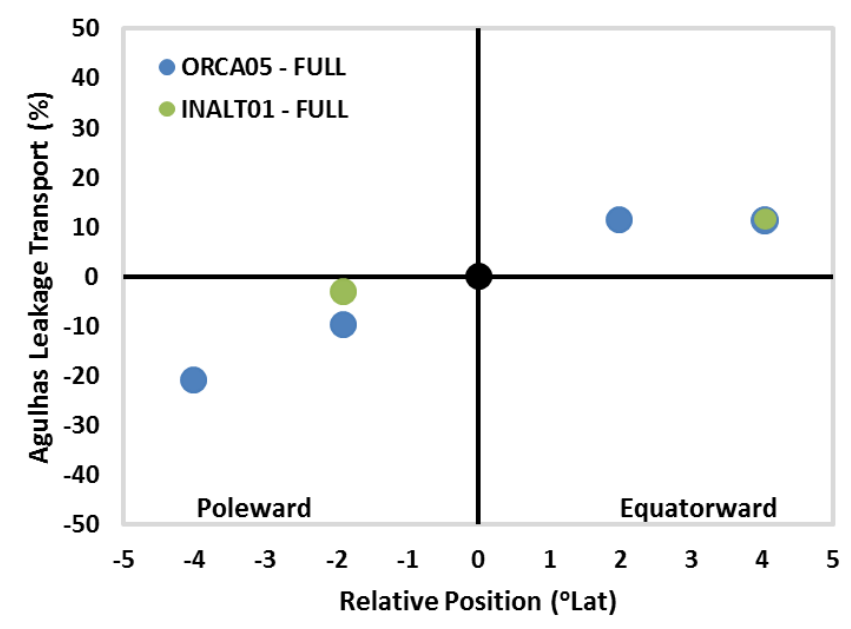

(b) SHW - Intensity

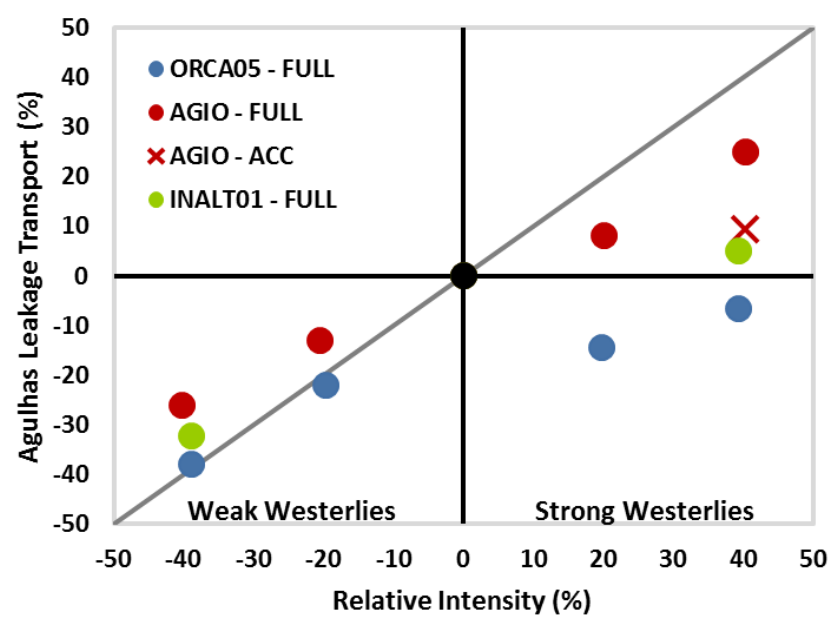

(c) SHW - Intensity Decomposition

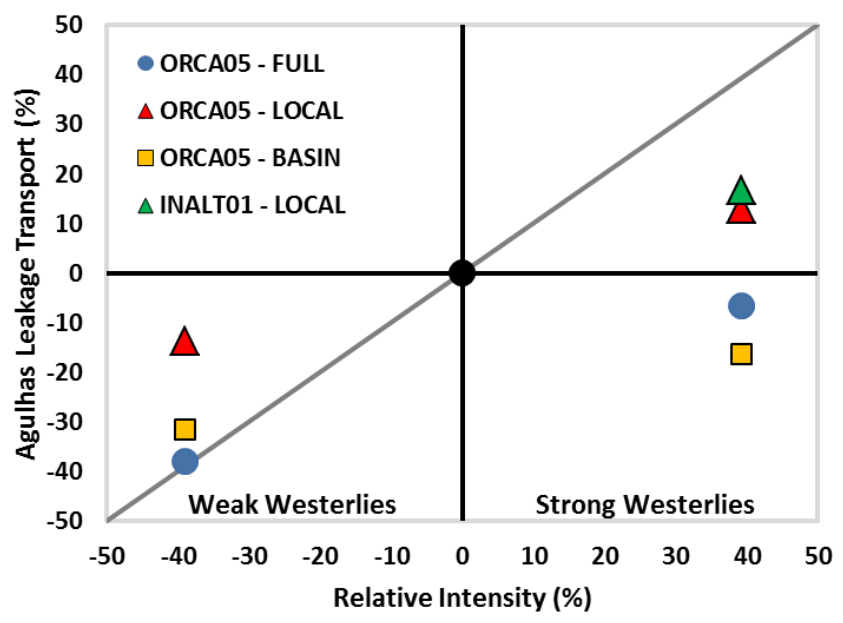


1042 FIG. 6. Change in Agulhas leakage (\%) versus change in (a) position ( ${ }^{\circ}$ Lat) and (b \& c) 1043 intensity (\%) of the Southern Hemisphere westerlies (SHW). Reference values (black

1044 dot) are set at the origin for all three models and each dot represents a decade average

1045 (model years 51 - 60, blue shading in Fig. 2). (c) The decomposition between FULL,

1046 BASIN and LOCAL is shown for the SHW-40\% and SHW+40\% cases. The gray line in

1047 b \& c represent the theoretical change in Sverdrup transport.

1048

1049 

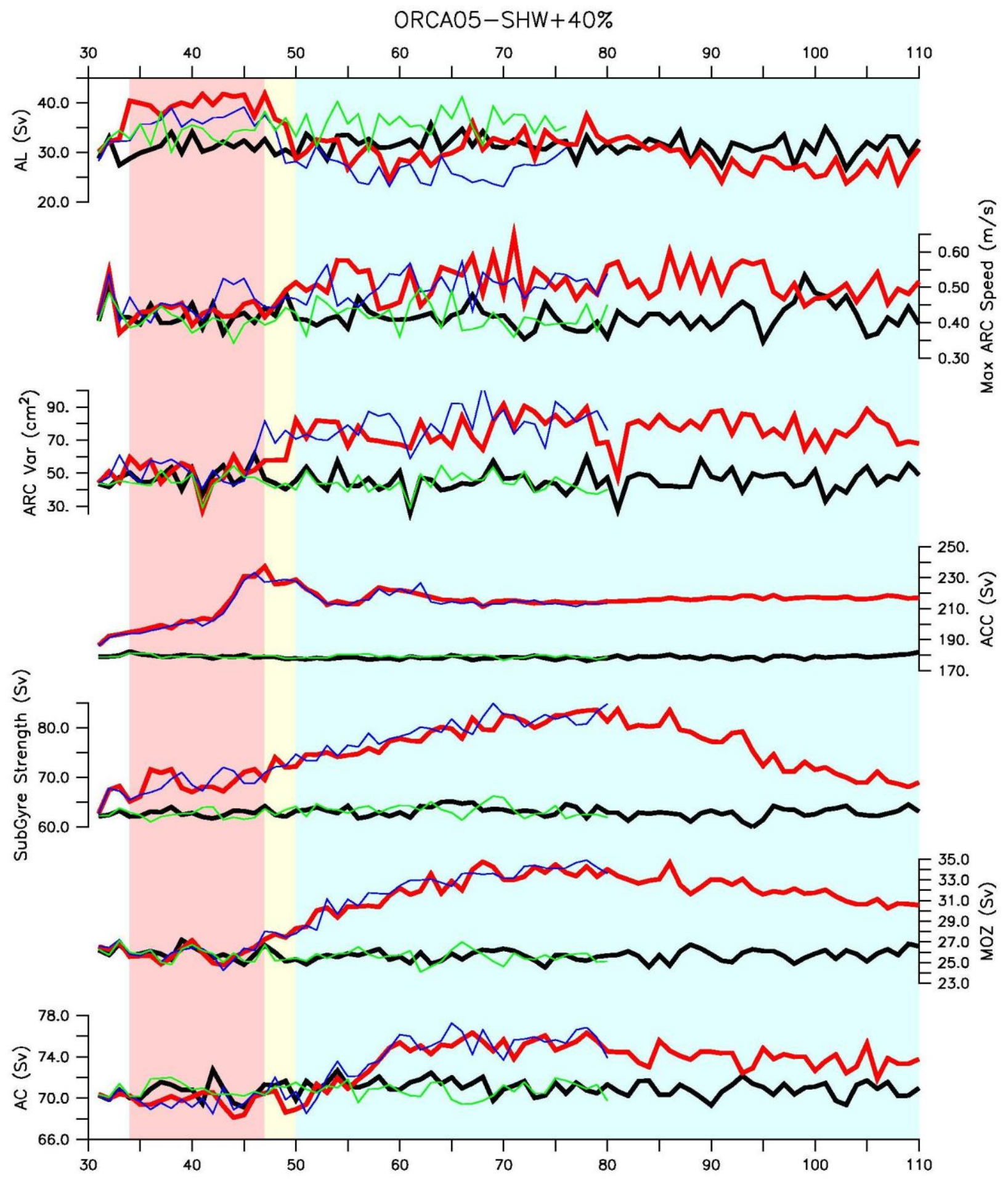

REF, FULL, BASIN, LOCAL 
1052 FIG. 7. Time-series for the REF and SHW+40\% cases within ORCA05. Sections used to 1053 measure the transports are shown in Fig. 5a and aside from the Agulhas leakage (AL), all 1054 transports are measured from the barotropic stream-function: the Antarctic Circumpolar 1055 Current (ACC) as the maximum stream-function south of Africa between $20^{\circ}$ and $30^{\circ} \mathrm{E}$; 1056 the sub-gyre strength as the minimum stream-function value between $30^{\circ}$ and $60^{\circ} \mathrm{E}$; the 1057 Agulhas Current (AC) as the minimum stream-function along the section at $32^{\circ} \mathrm{S}$. For the 1058 Agulhas Return Current (ARC), speed is for the top $1000 \mathrm{~m}$. The light red, yellow and 1059 blue shadings indicate Stage-1, Stage-2 and Stage-3 in ORCA05-SHW+40\%-FULL 1060 leakage response respectively (details in text). 

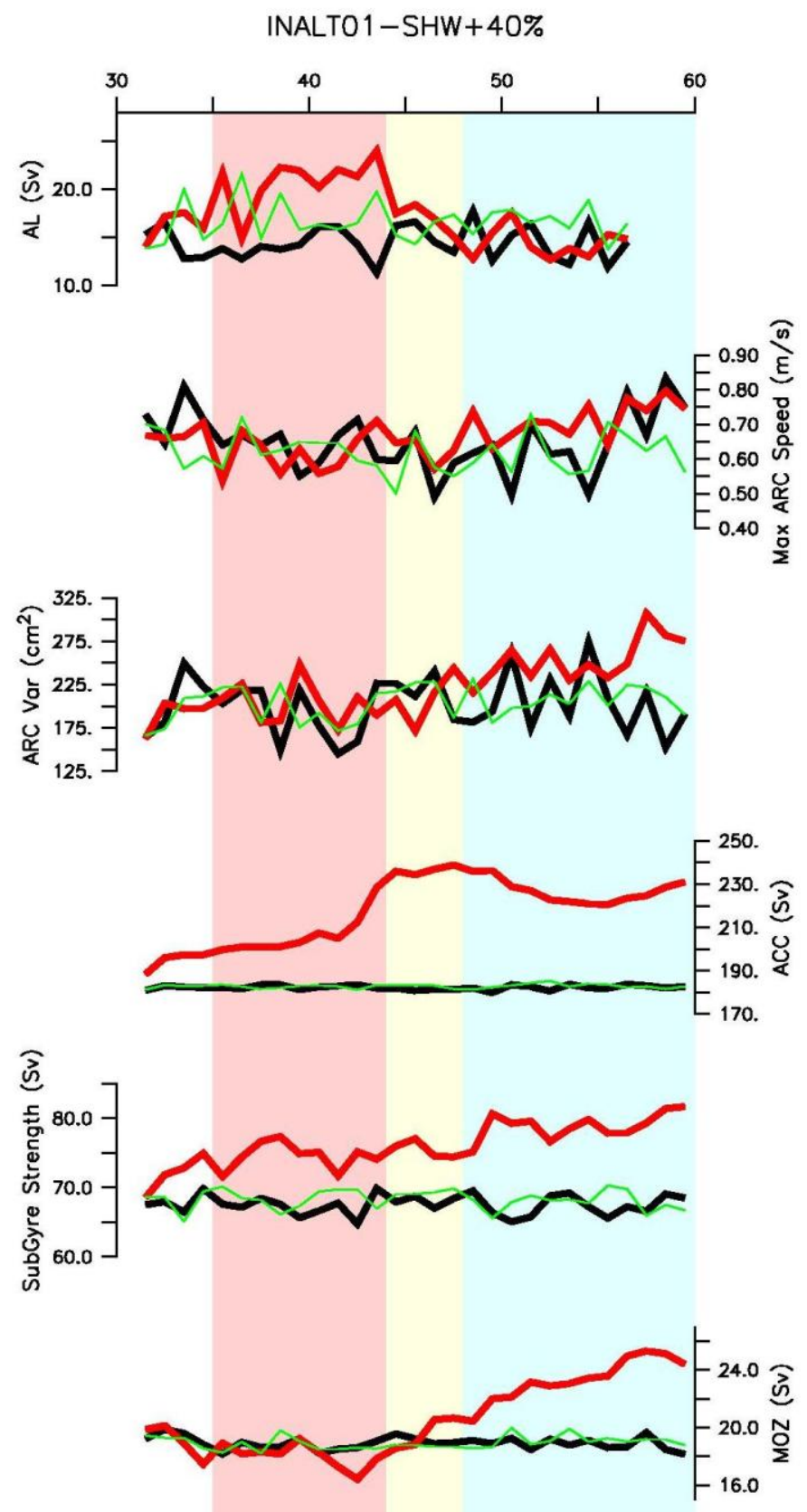

REF, FULL, LOCAL

1063 FIG. 8. Same as Fig. 7 for INALT01. 

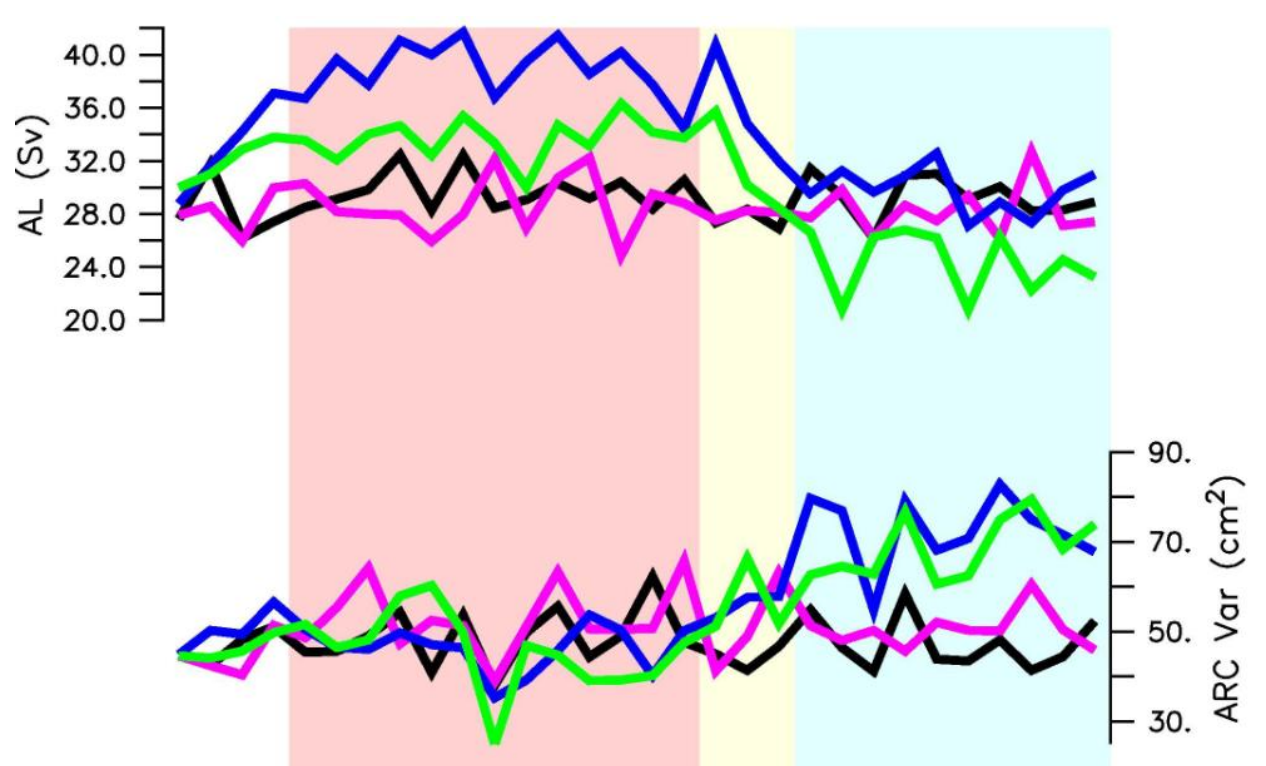

$$
\text { REF, ACC }-P, A C C-B, A C C-L
$$

1066 FIG. 9. Time-series of Agulhas leakage (AL), Agulhas Return Current variance (ARC

1067 Var) and Antarctic Circumpolar Current (ACC) transport from the ACC-P (pink), ACC-B

1068 (blue) and ACC-L (green) decompositions of the SHW+40\% anomaly within ORCA05.

1069 The light red, yellow and blue shadings indicate Stage-1, Stage- 2 and Stage-3 in

1070 ORCA05-SHW+40\%-FULL leakage response respectively (extracted from Fig. 7). 
1074

1075
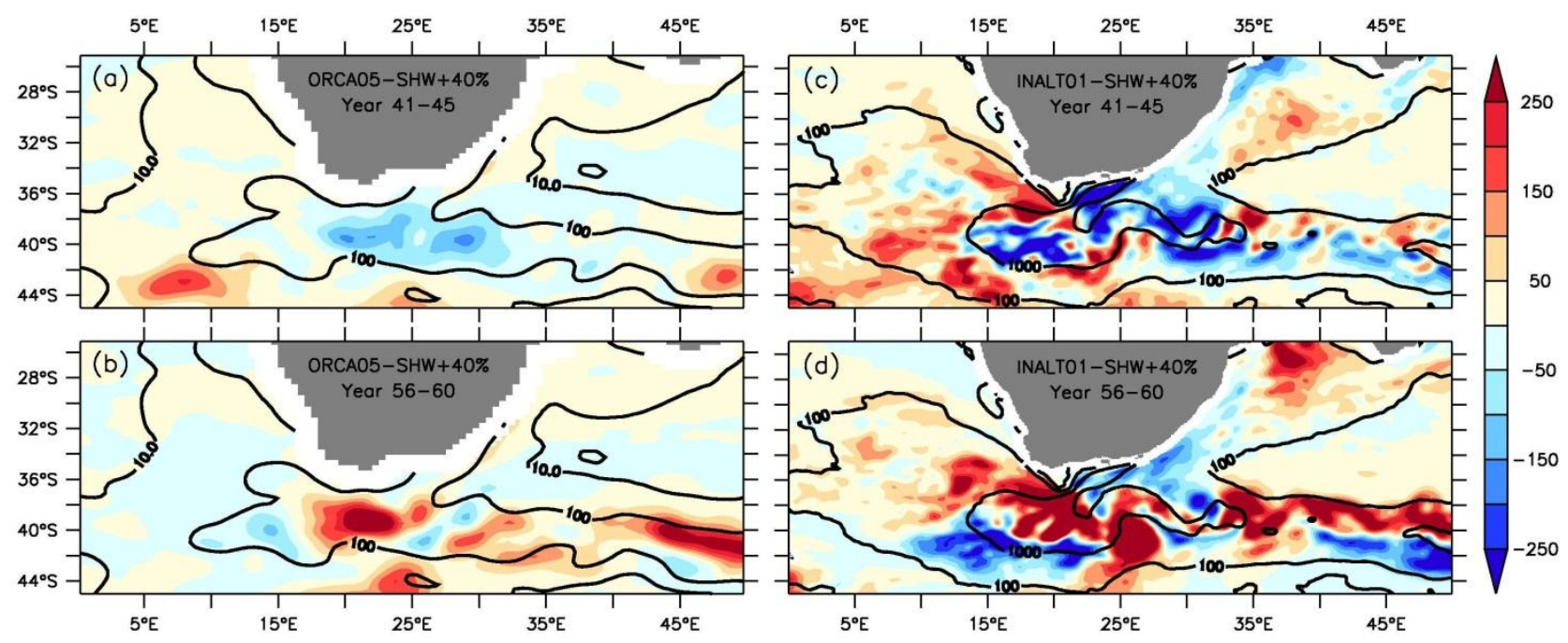

1076 FIG. 10. Eddy Kinetic Energy (EKE) per unit mass anomaly at $100 \mathrm{~m}\left(\mathrm{~cm}^{2} \mathrm{~s}^{-2}\right)$ within

1077 ORCA05 (left) and INALT01 (right) averaged over model years 41 - 45 (a \& c) and 56 -

107860 (b \& d). Contours indicate the respective averaged reference EKE values for model

1079 years $41-60$.

1080

1081 


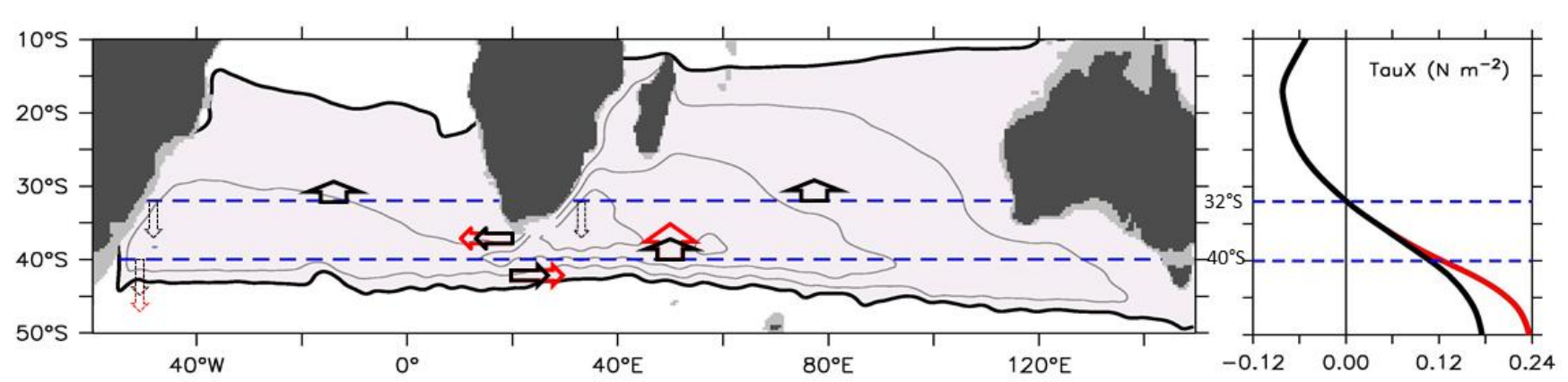

1083 FIG. 11. Schematic of the proposed mechanism of leakage response to the westerlies.

1084 Contours of barotropic stream function portray the anticyclonic supergyre (shaded area)

1085 connecting the South Indian and South Atlantic oceans, with thick black contour

1086 demarcating its boundaries (data extracted from ORCA05-REF experiment). Thick

1087 arrows indicate the meridional Sverdrup interior flow and the corresponding zonal

1088 transport that results from the wind stress application (REF in black and SHW+40\% case

1089 in red). The circulation is closed by the return flow of the western boundary currents

1090 (dotted arrows).

1091 


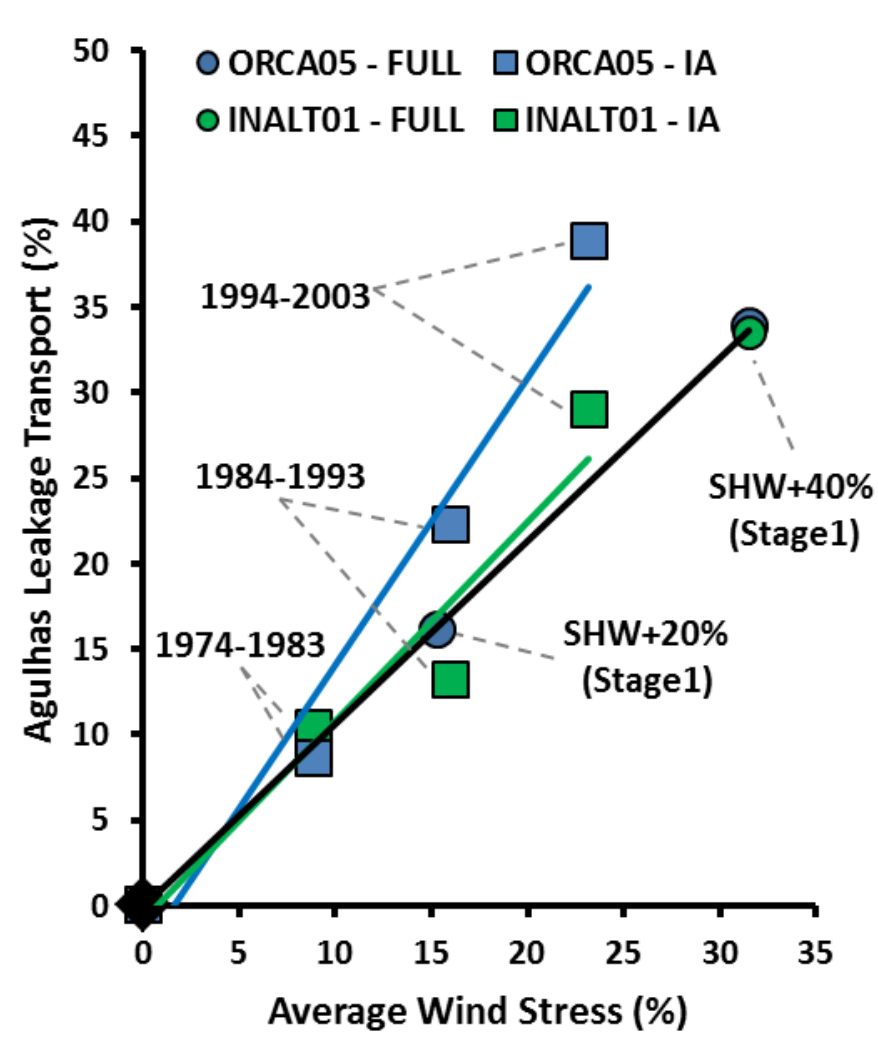

1093 FIG. 12. Change in Agulhas leakage (\%) versus change in wind stress (\%) averaged over

1094 the region $20^{\circ} \mathrm{W}-140^{\circ} \mathrm{E}, 35^{\circ}-65^{\circ} \mathrm{S}$. Squares represent decadal averages from hind-cast

1095 inter-annual (IA) simulations of ORCA05-IA (light blue) and INALT01-IA (light green),

1096 with the period 1964-1973 taken as reference (set at origin); Circles represent Stage-1

1097 averages (model years 41-45) from the FULL application of the SHW+20\% and

1098 SHW+40\% anomalies as well as the corresponding REF (set at origin) within ORCA05

1099 (blue) and INALT01 (green).

1100 